\title{
Psychological readiness: Is this assessment valuable to athletic trainers in understanding athletes' adherence and compliance
}

\author{
Damien Clement \\ West Virginia University
}

Follow this and additional works at: https://researchrepository.wvu.edu/etd

\section{Recommended Citation}

Clement, Damien, "Psychological readiness: Is this assessment valuable to athletic trainers in understanding athletes' adherence and compliance" (2005). Graduate Theses, Dissertations, and Problem Reports. 2302.

https://researchrepository.wvu.edu/etd/2302

This Thesis is protected by copyright and/or related rights. It has been brought to you by the The Research Repository @ WVU with permission from the rights-holder(s). You are free to use this Thesis in any way that is permitted by the copyright and related rights legislation that applies to your use. For other uses you must obtain permission from the rights-holder(s) directly, unless additional rights are indicated by a Creative Commons license in the record and/ or on the work itself. This Thesis has been accepted for inclusion in WVU Graduate Theses, Dissertations, and Problem Reports collection by an authorized administrator of The Research Repository @ WVU. For more information, please contact researchrepository@mail.wvu.edu. 
Psychological Readiness: Is this Assessment Valuable to Athletic Trainers in Understanding Athletes' Adherence and Compliance

\title{
Damien Clement, ATC
}

\author{
A thesis submitted to \\ the School of Physical Education \\ at West Virginia University \\ in partial fulfillment of the requirements for the degree of \\ Master of Science \\ in \\ Sport \& Exercise Psychology
}

Andrew C. Ostrow, Ph.D., Chair

Sam. Zizzi, Ed.D.

Roy Tunick, Ed.D.

School of Physical Education

Morgantown, WV

2005

Keywords: Psychological Readiness, Adherence, Compliance, Stages of Change, Processes of Change, Self Efficacy, Decisional Balance 


\begin{abstract}
Psychological Readiness: Is this Assessment Valuable to Athletic Trainers in Understanding Athletes' Adherence and Compliance

Damien Clement
\end{abstract}

Despite the many documented psychological reactions athletes experiences as a result of athletic injuries, very little, if any psychological assessment is being done to evaluate their readiness to embark on their rehabilitation. Consequently, the purpose of this study was to determine if psychological readiness influences athletes' adherence and compliance to their rehabilitation programs. A secondary purpose was to determine the impact psychological readiness had on perceived versus actual completion rates of rehabilitation programs. Injured college student athletes' $(N=70)$ psychological readiness were assessed (using the transtheoretical model of behavior change ${ }^{10}$ ) to determine its effect on compliance, adherence rates and perceived versus actual completion rates of rehabilitation programs. Results revealed that participants who were advanced in their stages of change generally reported an increase in self efficacy, utilization of pros as opposed to cons and use of behavioral when compared to experiential processes of change. No significant relationships were found between psychological readiness and athletes' adherence, compliance and their perceived versus actual completion rates of rehabilitation programs. 


\section{ACKNOWLEDGMENTS}

Although the completion of this research project entailed a great deal of work on my part quite a number of other individuals must be acknowledged for not only their guidance but also for the invaluable support they provided to me when at times I thought this project might not be completed.

I would like to thank my chair and advisor Dr. Andrew Ostrow for not only his patience but his knowledge, guidance and insight throughout this entire process. The time and effort you put into ensuring I successfully completed this project in my opinion was unparalleled. I wish I could express in words the gratitude I have for the dedication you exhibited in ensuring that I put forth the best possible work I could produce. Furthermore, the knowledge you imparted on me about the entire research process especially the pitfalls I experienced as a result of data collection will be surely remembered.

I would also like to thank Dr. Sam Zizzi for serving on my committee and providing me with support and feedback about this project. Your encouragement during this process was immensely beneficial. Furthermore, your statistical insight and knowledge were extremely helpful throughout this whole process.

I am also grateful to Dr. Roy Tunick for his help, feedback, and support with my thesis. I appreciate the time you took out of your schedule to serve as one of my committee members and for the insightful and knowledgeable comments and guidance you have provided me while completing this project.

I would also like to thank Kevin Kotsko and the athletic training staff of the Shell Athletic Training Room. Without their help this project would not have been possible. A special acknowledge must be given to Kevin Kotsko because when data collection slowed at the end of the spring semester 2005 he assured me that I would get my minimum sample size the following semester. True to his word I was able to get my sample size. Thank you Kevin! I would also like to acknowledge those injured athletes who took the time to complete my surveys which provided me with data needed to complete this project. Without your help, this project would not have been completed. Thank you again!

I would also like to thank my friends and colleagues in the Sport and Exercise Psychology Program. The many words of wisdom and encouragement I received from you all surely made this process seem achievable.

Finally, I would like to thank my Lord and Savior Jesus Christ, without him I would not have been able to complete this project nor be able to pursue my dream of completing a doctorate in Sport and Exercise Psychology. All the praise and glory to him and with his blessing and wishes I will continue to succeed in life. 


\section{TABLE OF CONTENTS}

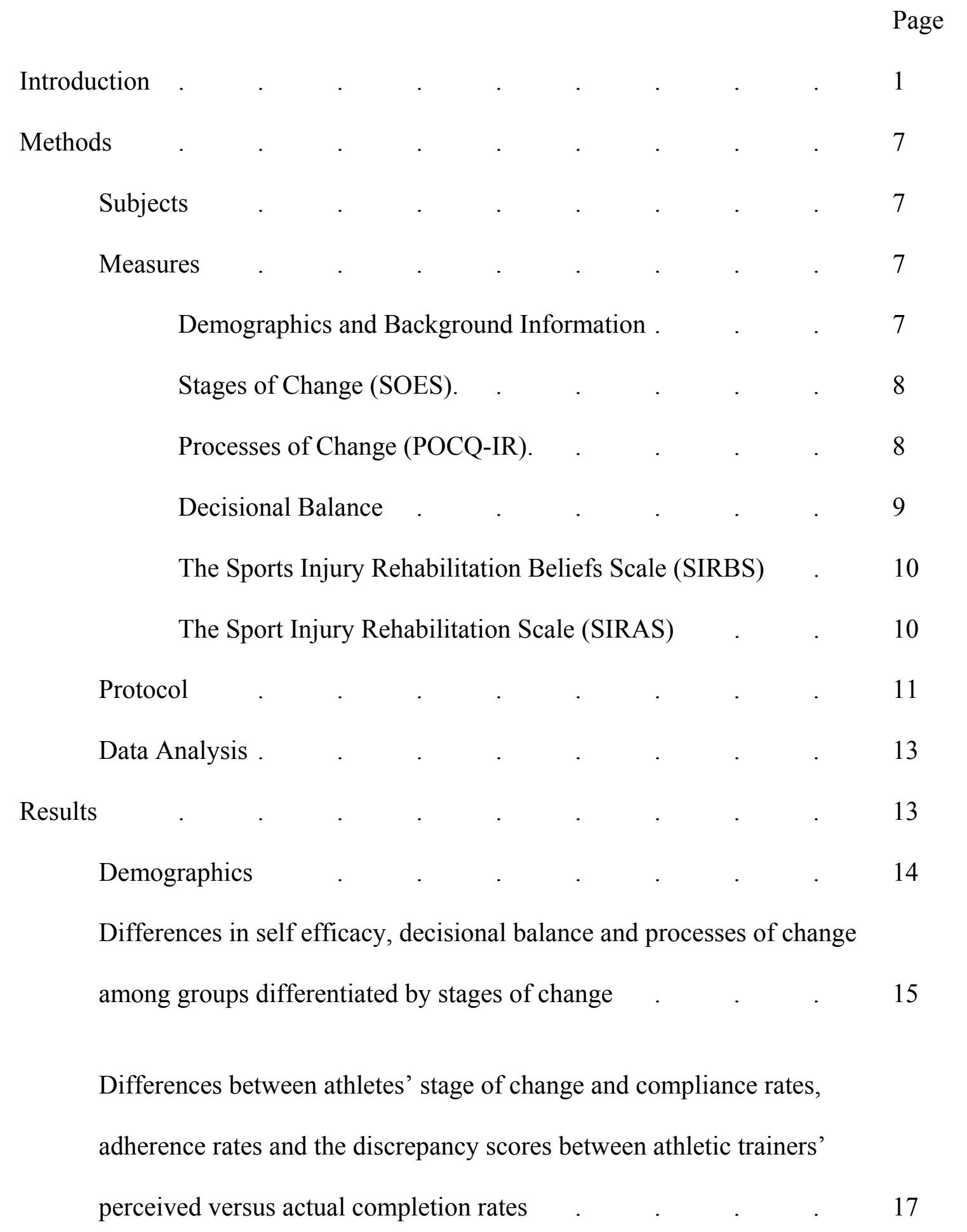


Predictability of athletes' scores on self efficacy, decisional balance and processes of change in predicting compliance rates, adherence rates and the discrepancy scores between athletic trainer's perceived versus actual completion rates.

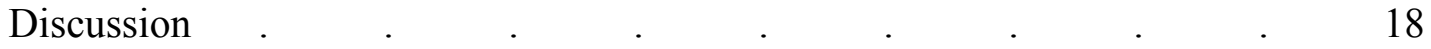

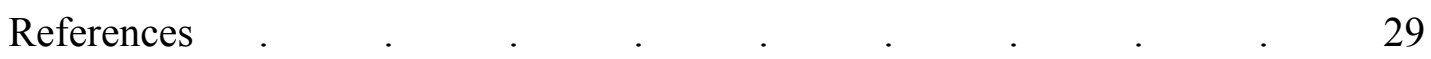

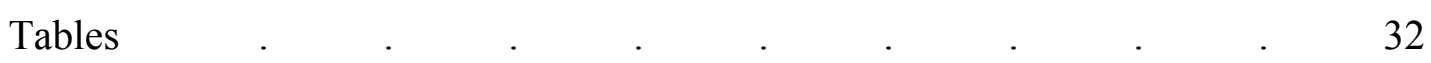

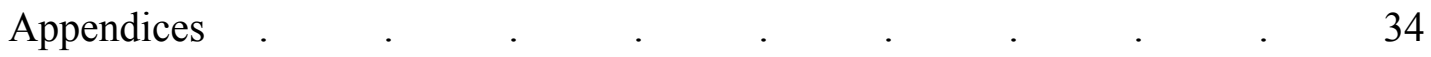

Appendix A- Athlete's Demographic Questionnaire $\quad$. $\quad$. 34

Appendix B- Athletic Trainers' Demographic Questionnaire . 36

Appendix C- Stage of Change Instrument $\quad$. $\quad$. $\quad$. $\quad$. 38

Appendix D- Injury Rehabilitation Survey . $\quad$. $\quad$. $\quad$. 40

Appendix E- Sport Injury Rehabilitation Adherence Scale. . 45

Appendix F- IRB Approval Letter. $\quad . \quad$. $\quad$. $\quad$. $\quad$. 47

Appendix G- Permission Responses to use Measures. $\quad 48$

Appendix H- Health Belief Model $\quad . \quad$. $\quad$. $\quad$. $\quad$. 49

Appendix I- Theory of Reasoned Action $\quad$. $\quad$. $\quad$. $\quad$. $\quad 51$

Appendix J- Theory of Planned Behavior $\quad$. $\quad$. $\quad$. $\quad 53$

Appendix K- Decision Making Model $\quad$. $\quad$. $\quad$. $\quad$. 55

Appendix L- Protection Motivation Model . $\quad$. $\quad$. $\quad 57$

Appendix M- Transtheoretical Model $\quad . \quad$. $\quad$. $\quad$. 59

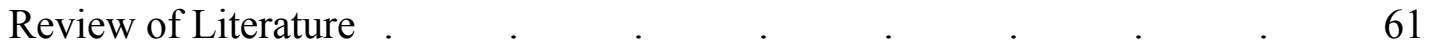




\section{LIST OF TABLES}

Page

Table 1- Demographic Characteristics of Injured Athletes- $(N=70)$

Table 2- Descriptive statistics for three stages of change groups for-

Self efficacy, decisional balance, processes of change, compliance rates adherence rates and discrepancy scores between perceived versus actual completion rates of rehabilitation scores 
Rehabilitation, because it is the final stage of the injury process, is considered very crucial to injured athletes returning to competition. ${ }^{1}$ Athletes are usually ushered into rehabilitation programs when their bodies are, from a medical standpoint, close to returning to their previously uninjured level. However, medical personnel must also take into consideration the fact that injury not only causes physical harm but it also presents a challenge to the maintenance of emotional equilibrium. ${ }^{2}$ Research has shown that some athletes, upon sustaining injuries experience psychological reactions such as depression, impaired self-esteem, and anxiety. ${ }^{3,4}$ Furthermore, Weiss and Weiss ${ }^{5}$ stated that athletes sometimes expressed an inability to cope with their injuries which manifests itself into feelings such as scariness, guilt, inadequacy and loss of control. These feelings are believed to influence rehabilitation both directly and indirectly. ${ }^{6}$

Rehabilitation, according to the literature, seems to be plagued by adherence problems. ${ }^{1}$ Medical personnel have always believed that athletes would be motivated and committed to their rehabilitation programs; however, the possible discomfort and the ensuing pain could possible encourage non adherence. ${ }^{1}$ Furthermore, studies by Brewer ${ }^{7}$ and Daly, Brewer, Van Raalte, Petipas and Sklar ${ }^{8}$ have shown that psychological responses to injury also influence athletes' adherence. Among the psychological responses found to be negatively associated with adherence to rehabilitation programs are anger, depression, fear, tension, disgust, anxiety and panic.

However, despite the many documented effects psychological responses to injuries are thought to have, very little, if any psychological assessment is done on athletes to evaluate their readiness to embark on this phase of the injury recovery process. This assessment has been largely overlooked until Udry, Shelbourne and Gray ${ }^{9}$ 
investigated the usefulness of evaluating the psychological readiness of patients prior to anterior cruciate ligament (ACL) surgery. Using a sample of 121 pre ACL subjects, these researchers used the Stages of Change Model $^{10}$ to assess participants' psychological readiness. The participants were assessed via the use of questionnaires on their self efficacy levels, decisional balance and their usage of the processes of change. Results revealed that participants who were deemed psychological ready for surgery and rehabilitation exhibited high levels of self efficacy, perceived more pros than cons and utilized more behavioral as opposed to experiential processes of change. Furthermore, the researchers concluded that "it would be advantageous to screen patients preoperatively relative to their psychological readiness for surgery and rehabilitation." ${ }^{\prime 9}$ No mention, however, was made of how well these patients adhered to their post surgical rehabilitation which would provide validity for the model.

Based on the aforementioned results these researchers suggested, among other things, that further research should be conducted to assess the effect that psychological readiness possibly has on rehabilitation adherence. Udry, Shelbourne and Gray ${ }^{9}$ further postulated that research needs be done to examine the effect psychological readiness has on the completion rates of rehabilitation programs. Medical personnel usually suggest a predetermined range of time, based on the nature of injury, that an injured athlete should spend in rehabilitation. However, the effect that psychological readiness has on the perceived amount of time that an athlete should spend in rehabilitation has not been studied. Furthermore, as highlighted earlier, rehabilitation has been plagued with adherence and compliance problems. These problems may arise due to the strict sequential nature with which athletes are ushered into rehabilitation without any regards 
to their psychological readiness for this stage of the injury process. However, the exact impact that psychological readiness has on compliance and adherence rates has also not been studied.

This psychological readiness can be assessed using the Transtheoretical Model (TTM) of behavior change. ${ }^{10}$ This model, according to the literature, provides an excellent framework for investigating how people adapt to new behaviors. In this case, embarking on rehabilitation can be likened to adopting a new behavior. Additionally, the adaptability of this model has been demonstrated in its application to a variety of behavior changes such as exercise, protection from sun exposure, smoking, and dietary consumption. ${ }^{11}$ Within these studies the TTM has helped practitioners understand an individual's readiness to embark on a new behavior in addition to encouraging them to match any possible interventions to help them in adapting to their new behaviors. Thus, the TTM could be quite beneficial in assessing athletes' readiness to embark on rehabilitation programs.

This model was initially developed to assess the processes that individuals go through enroute to a behavior changes. The original central constructs of this model were the stages of change and the processes of change. The stages of change are thought to reflect the varying degrees of readiness experienced by individuals as they embark on new behaviors. $1^{2}$ Prochaska and DiClemente ${ }^{10}$ postulated that the TTM consists of five different stages: precontemplation (no intention of making any changes), contemplation (considering making some changes), preparation (making small changes), action (actively participating in the new behavior) and maintenance (continuing the new behavior over an extended period of time). 
The processes of change are thought to be the techniques and strategies used by individuals as they move through the aforementioned stages. ${ }^{10}$ These ten processes of change are consciousness raising, dramatic relief, environmental reevaluation, social liberation, self reevaluation, counterconditioning, helping relationships, reinforcement management, stimulus control and self liberation. These ten processes are thought to be split into experiential and behavioral processes. Experiential processes focus on the individual's awareness and the feelings experienced while embarking on the behavior change. Behavioral processes, however, refer to the overt activities which an individual will engage in during the course of behavior modification. Studies have found that as individuals progress through the stages of change they will rely more heavily on experiential processes in the earlier stages and more on the behavioral processes in the later part of their stages of change. ${ }^{12,13}$

Self efficacy is an additional construct that has been incorporated into the TTM. Self efficacy refers to the confidence an individual has in his/ her ability to perform a behavior. ${ }^{14}$ Research has shown that self efficacy increases as an individual moves through the stages of change. ${ }^{13}$ Wong ${ }^{15}$ in an injury rehabilitation study confirmed the aforementioned statement by stating that a significant relationship does exist between self efficacy and stages of change. Results from this study revealed that self efficacy scores were found to be higher among individuals in the maintenance stage when compared to those in action. Furthermore, self efficacy scores among those individuals in the action stage were found to higher than those in the preparation stage.

The final construct of the TTM, decisional balance, is derived from the Decision Making model. ${ }^{16}$ This construct is thought to assess the benefits versus the costs of 
embarking on a new behavior. Marcus, Rakowski and Rossi ${ }^{17}$ were able to show the distinct differences in participants' perceptions of the pros (eg, "I will feel more confident if I rehabilitated regularly") and cons (eg, "Regular rehabilitation takes up too much of my time") across the stages of change. They found that the cons out numbered the pros in the earlier stages of the stages of change while the pros out numbered the cons in contemplation through maintenance stages. Furthermore, Prochaska, Velicer, Guadagnoli, Rossi and Di Clemente ${ }^{18}$ have been able to show that this construct have been very useful in predicting behavior changes and movement through the stages of the TTM.

As previously mentioned athletes are usually ushered into rehabilitation when their bodies are deemed healed but not yet ready to return to the field of play. It is debatable in the literature how much consideration is being given to athletes' psychologically readiness prior to embarking on this stage of the injury recovery process. This study could possibly advance the understanding of psychological readiness and its effect on rehabilitation. As alluded to earlier, injury not only causes physical harm but it may also disturbs an individual's emotional equilibrium. ${ }^{2}$ This disturbance could possibly influence an athlete in any number of ways, resulting in that individual not being ready to commence such a rehabilitation program. By assessing athletes' psychological readiness the athletic training staff may get an indication of which athletes are mentally ready for rehabilitation. Consequently, as they become aware of athletes who are not ready for this stage of the injury recovery process suitable interventions could be utilized and appropriate referrals made. Additionally, this assessment could possibly help in the 
construction and tailoring of rehabilitation programs to meet athletes' needs in order to facilitate their entry back to the field of play.

Although the use of the TTM has been limited to health behaviors, it has been used within the field of sport and exercise psychology as evidence by its application to the adoption of psychological skills. ${ }^{19}$ Leffingwell, Rider, and Williams ${ }^{19}$ not only demonstrated the TTM applicability to the field but also the internal reliability and content validity of the three measures which make up the TTM- stages of change, self efficacy and decisional balance. ${ }^{19}$ There has, however, not been very much application of this model to injury rehabilitation. Wong ${ }^{15}$ has been the pioneer with her application of the TTM to injury rehabilitation.

Therefore, due to the dearth of research in this area and the applicability of the TTM, one of the main purposes of this study was to validate the stages of change construct in relation to injury rehabilitation. Another purpose of this study was to assess the impact psychological readiness (as assessed by the TTM) had on athletes' adherence and compliance rates with respect to their rehabilitation programs. Lastly, the impact that psychological readiness had on perceived versus actual completion rates of rehabilitation programs will also be investigated. It was postulated, based on the theoretical literature and the intuition of the researcher, that across the stages of change individuals will be rated as psychologically ready if they a) are more advanced in their stages of change, b) rate themselves higher in self efficacy, c) indicate utilizing more pros than cons and d) utilize experiential processes earlier while using more behavioral processes later in the rehabilitation process. It was also hypothesized that individuals who have been deemed psychologically ready will a) comply more closely to their rehabilitation program, b) 
adhere more closely to their rehabilitation programs and c) complete their rehabilitation programs in close proximity to the estimated time given by the athletic trainer as opposed to those who are deemed less psychologically ready.

\section{METHODS}

\section{Subjects}

Injured athletes $(N=70)$ were recruited as participants in the study during the fall and spring semesters of the 2004-2005 academic year and also during the fall semester of the 2005-2006 academic year by one of the head athletic trainers of a large Mid Atlantic Division I Institution. All participants sustained their injuries during their off season, during training, or during competition. These injuries sustained were categorized as either second degree $(N=44 ; 62.9 \%)$ or third degree injury $(N=26 ; 37.1 \%)$. Males made up $55.7 \%$ of the sample whereas females made up $44.3 \%$ of the sample. In addition, the majority of the sample $(37.1 \%)$ indicated they were in the freshman year of their studies. The most prominent sport among participants was men's soccer $(38.5 \%)$ followed by women's soccer (31.5\%) and wrestling (12.8\%).

\section{MEASURES}

\section{Demographics and Background Information}

Demographic and background information were obtained from both the participants and the athletic trainer via a demographic questionnaires consisting of open ended questions, closed ended questions and subjective rating questions. Demographic information provided for injured athletes consisted of participants' ages, gender, varsity sport he/she participated in, and the season in which the injury occurred. Furthermore, background information with respect to participants' previous involvement in 
rehabilitation was also obtained. Demographic information solicited from the athletic trainer consisted of the number of years he has been involved in athletic training and the number of years he has been at the present institution.

\section{Stages of Change}

Participants' Stages of Change was assessed using a modified version of Stages of Exercise Scale $\left(\mathrm{SOES}^{20}\right)$. The $\mathrm{SOES}^{20}$ recognizes that individuals may be at different degrees of readiness with respect to the adaptation of an exercise behavior. As a result, this instrument consists of a ladder-like diagram, with each rung representing one of the five stages of change. This instrument is rated on a 5-point ordinal scale ranging from $0=$ precontemplation to $4=$ maintenance. This instrument was modified by Wong ${ }^{15}$ to now include references to rehabilitation. Minor word changes were, however, made by the investigator to make this instrument more specific for this study. For example in the original $\mathrm{SOES}^{20}$ an item would have read "I presently do not exercise but I have been thinking about starting to exercise." The modified version of this item would be "I do not currently rehabilitate my injury but I am thinking about starting to do so.” Participants were asked to indicate, on the ladder, which of the five stages best represented their situation. Concurrent validity of the $\mathrm{SOES}^{20}$ was established by comparing the $\mathrm{SOES}^{20}$ to three physical indices and test-retest reliability was established with Spearman's rho for the $\operatorname{SOES}^{28}$ being $1.00\left(\right.$ p.0001). $^{20}$

\section{Processes of Change}

The processes of change experienced by participants they embarked on their

rehabilitation program was assessed using Wong ${ }^{15}$ slightly modified version of the Process of Change Questionnaire for Injury Rehabilitation (POCQ-IR). No further 
modifications were made by the investigator. The POCQ-IR consists of 10 subscales each with 3 questions for a total of 30 items. Participants responded using a 5-point ordinal scale, ranging from $1=$ never to $5=$ frequently, on how frequently they utilized experiential or behavioral processes of change during their rehabilitation. The POCQ-IR had previously been modified to make it more specific to rehabilitation. For example on the original POCQ-IR, an item read "I recall information people have personally given me on the benefits of exercise." The modified version of this item now read "I recall information people have personally given me on the benefits of rehabilitating my injury." Internal reliability coefficients for all the scales of the POCQ-IR ranged from 0.71 to 0.88 with the exception of conscious raising. This, however, was resolved by the elimination of the first item of that scale which resulted in a Cronbach alpha of $0.70 .^{9}$

\section{Decisional Balance}

Participants' decisional balance with respect to their involvement in rehabilitation was assessed using a modified version of a sixteen-item measure initially used by Marcus and Owen. ${ }^{21}$ This instrument was further modified by Udry, Shelbourne and Gray ${ }^{9}$ to make it more specific to rehabilitation. This measure consisted of 10 items representing pros and 6 items representing cons with respect to exercise. Participants responded to these items on a 5 -point ordinal scale ranging from $1=$ not very important to $5=$ extremely important depending on whether they assessed those items as having served as benefits or costs during the course of their rehabilitation. Like the $\operatorname{SOES}^{20}$ the decisional balance instrument was also slightly modified, by the investigator, to include references more specific to rehabilitation. For example on the original decisional balance instrument an item read "I would have more energy for my family and friends if I exercised regularly." 
The modified version of this new item now read "I would have more energy for my family and friends if I rehabilitated regularly." Internal consistency for the pro scale was 0.87 whereas it was 0.90 for the con scale. ${ }^{22}$ Furthermore, principal component analyses revealed both scales were stable across samples, thus, supporting the construct validity of the measure. ${ }^{22}$

\section{The Sports Injury Rehabilitation Beliefs Survey}

The Sports Injury Rehabilitation Beliefs Survey $\left(\mathrm{SIRBS}^{23}\right)$ was used to assess participants' expectations of rehabilitation. The SIRBS ${ }^{31}$ consists of 19 items. Participants respond to each item on a 7 - point Likert scale ranging from $1=$ very strongly disagree to $7=$ very strongly agree. This instrument consisted of 5 subscales which assessed participants' belief in their susceptibility, treatment efficacy, self efficacy, rehabilitation value and injury severity. No modifications were made to this injury because it was already rehabilitation specific. Cronbach alpha reliability coefficients of 0.79 (self efficacy), 0.83 (treatment efficacy), 0.83 (susceptibility) and 0.63 (injury severity) were reported for the SIRBS. ${ }^{23}$ However, for the purposes of the current study only the self efficacy subscale was used during data analysis.

\section{The Sport Injury Rehabilitation Scale}

The Sport Injury Rehabilitation Adherence Scale $\left(\operatorname{SIRAS}^{24}\right)$ was used to assess participant's compliance to their rehabilitation procedures. The $\operatorname{SIRAS}^{24}$, a 3-item instrument, was initially developed from adherence literature by Brewer, Van Raalte, Petipas, Skar, Pohlman, Krushell, Ditmar, Daly and Weinstock. ${ }^{24}$ Although, developed to do the aforementioned, the SIRAS ${ }^{24}$ can also assess compliance with instructions. ${ }^{7}$ Athletic trainers rated participants using a 5-point ordinal scale ranging from $1=$ 
minimum effort to $5=$ maximum effort on their ability to complete their rehabilitation exercises with the required intensity, the frequency with which they followed instructions and the degree to which these athletes were receptive of changes made in their rehabilitation programs. ${ }^{24}$ Internal consistency of the SIRAS ${ }^{24}$ was found to be 0.82 and test-retest reliability was found to $0.81 .^{24}$ Validity was established when participants scores on the measure were found to be correlated $(r=.21, p<.05)$ with attendance at rehabilitation sessions. $^{24}$

\section{Protocol}

Prior to commencing this study a pilot study was conducted to orient the athletic trainers to the study of what was being done and what would be expected of him. More importantly, this pilot study was used to determine if any changes should have been made to the methodology of the study in addition to gaining feedback on the clarity of the questionnaires and the instructions provided to the athletic trainer. Results from the pilot study revealed that no significant changes needed to be made to the questionnaires and the athletic trainer understood what was expected of him. Prior to commencing the actual study approval had been obtained from the Institutional Review Board for the Protection of Human Subjects and informed consent was obtained from each participant.

Inclusion criteria for this study was as follows; participants had to be over the age of eighteen, and must have sustained an injury either during their off season (immediately preceding their competitive season), training or during competition. Additionally, these injuries should have been, at a minimum, second degree injuries as evaluated by the athletic trainers. 
Once prospective athletes met those criteria they were asked by the athletic trainers to participate in the study. After obtaining informed consent participants were then asked to complete a demographic questionnaire. They then completed the stages of change instrument, the processes of change questionnaire, the sports injury rehabilitation beliefs survey and the decisional balance questionnaire. These questionnaires were administered in random order to reduce the possibility of a testing effect. Furthermore, participants were asked to complete these questionnaires based on their current injury and their reactions to their impending rehabilitation. These questionnaires were distributed to the participants by the athletic trainer.

Once questionnaires were completed they were placed in a sealed envelope provided. All of these sealed envelopes were stored in a locked cabinet in the athletic trainer's office until retrieved by the researcher. Upon a participant's completion of their rehabilitation program the athletic trainer completed the SIRAS ${ }^{32}$ instrument with regards to that particular participant's compliance to their rehabilitation program. This completed instrument was also placed in a sealed envelope and stored in the athletic trainer's office until retrieved by the researcher. Adherence records were then obtained from treatment logs and recorded by the researcher. Lastly, the researcher obtained from the treatment $\log$ the length of time the athlete spent in rehabilitation and compared this time to the athletic trainer's initial perception of the amount of time the athlete should have spent in rehabilitation. The athletic trainer's perceptions was obtained when participants first completed the questionnaire at the onset of the study. During the course of the study the researcher spent a total of seven hours each week in the athletic training room in an attempt to obtain sufficient participants for the study in addition to ensuring that the 
athletic trainer was complying with recruitment and distribution procedures. When the study was completed the researcher sent thank you cards to the athletic training staff for their time and effort.

\section{Data Analysis}

Firstly, descriptive statistics were calculated for selected variables used in the study. Secondly, analyses were run to determine the internal reliability of the measures used in the study. Thirdly, one-way ANOVAs were used to examine the differences between stages of change and self efficacy, pros and cons, experiential and behavioral processes of change. One-way ANOVAs were also used to determine if individuals who were advanced in the stages of change adhered, complied or differed in the discrepancy between the athletic trainer's perceived versus actual completion time of their rehabilitation programs when compared to those lower in the stages of change. Lastly, multiple regression analyses were performed to determine which variables (self efficacy, pros and cons, and experiential and behavioral processes of change) were significant predictors of adherence rates, compliance rates and the discrepancy score between the athletic trainer's perceived versus actual completion rates of rehabilitation programs.

\section{Results}

Participants in the study were asked to rate themselves into one of the five stages of change with respect to their psychological readiness for rehabilitation. Frequency scores were used to determine the distribution among the five possible groups. The classifications and frequencies for the stages were as follows: precontemplation $(n=18$; $11.4 \%)$, contemplation $(n=16 ; 22.9 \%)$, preparation $(n=28 ; 40 \%)$, action $(n=18 ; 25.7 \%)$ and maintenance $(n=0 ; 0 \%)$. Due to the distribution of scores and in an effort to 
maximize statistical power, the participants indicating that they were in precontemplation or contemplation stages were combined into one group. Thus, three stages of change groups were examined and compared: precontemplation/ contemplation, preparation and action. Previous research by Wong ${ }^{15}$ has shown precedence for collapsing these stages to maximize statistical power. Table 2 presents the means and standard deviations for self efficacy, decisional balance- pros and cons, experiential and behavioral processes of change, compliance scores, adherence percentages and discrepancy scores between perceived versus actual completion rates of rehabilitation for the three assigned stages of change groups.

\section{Demographics}

Approximately, $52.9 \%$ of the sample indicated that their injuries occurred in the pre-season. An evaluation of findings from the demographic information sheet also revealed that $78.6 \%$ of the participants had previously attended rehabilitation with a further $55.7 \%$ indicating they had attended rehabilitation for their current injury. Lastly, participants rated their mean past rehabilitation experience as a $3.96(S D=0.96)$ on a 5point scale (ranging from $1=$ very negative to $5=$ very positive) while also indicating mean ratings of $3.39(S D=0.91)$ and $3.14(S D=0.95)$ respectively (on 5- point scale) when asked about the amount of stress they were currently experiencing and the degree to which they were finding their injury difficult to deal with. Please refer to Table 1 for more detailed demographic information. With respect to the demographic information for the athletic trainers, only one athletic trainer was used in the study and this male individual has been at the institution for 6 years and has been involved in athletic training 
for the past 10 years. Lastly, it must be mentioned that the sample size was, in fact $(N=73)$; however, three surveys were not used in the data analyses due to missing data. Are there differences in self efficacy, decisional balance and processes of change among groups differentiated by stages of change?

\section{Self Efficacy}

A one-way ANOVA comparing the three stages of change groups on self efficacy with a follow up Turkey pos hoc statistical analysis indicated that the action groups' mean score on self efficacy was significantly higher than the mean self efficacy score of the precontemplation/ contemplation group, $F(2,67)=17.30, p<.01, \mathrm{ES}=0.34$.

Furthermore, the mean self efficacy score for the preparation group was also found to be significantly higher than the mean self efficacy score for precontemplation/ contemplation group. However, there was no statistically significant differences in mean self efficacy scores between the preparation and action groups. Cronbach alpha for the self efficacy scale was found to 0.96 .

\section{Decisional Balance-pros}

A one-way ANOVA comparing the three stages of change groups on pros with a follow up Turkey pos hoc statistical analysis indicated that the action groups' mean score on pros was significantly higher than the mean pros score of the precontemplation/ contemplation group, $F(2,67)=13.21, p<.01, \mathrm{ES}=0.28$. Additionally, the mean pros score for the preparation group was also found to be significantly higher than the mean pros score for the precontemplation/ contemplation group. Nevertheless, there was no statistically significant of differences in mean pros scores between the preparation and action groups. Cronbach alpha for the pro items used in this study was 0.92 . 


\section{Decisional Balance-cons}

A one-way ANOVA comparing the three stages of change groups on cons with a follow up Turkey pos hoc statistical analysis indicated that the action groups' mean score on cons was significantly lower than the mean cons score of the precontemplation/ contemplation group, $F(2,67)=12.71, p<.01, \mathrm{ES}=0.28$. The mean cons score for the preparation group was also found to be significantly lower than the mean cons score for the precontemplation/ contemplation group. Lastly, there were no statistically significant differences in mean cons scores between the preparation and action groups. The Cronbach alphas score for the cons scale was found to be 0.86 .

\section{Processes of Change-experiential}

A one-way ANOVA comparing the three stages of change groups on experiential processes with a follow up Turkey pos hoc statistical analysis indicated that the action groups' mean score on experiential processes was significantly lower than the mean experiential processes score of the preparation group, $F(2,67)=18.54, p<.01, \mathrm{ES}=0.36$. Furthermore, the means experiential processes score for the preparation group was also found to be significantly lower than the mean experiential processes score for the precontemplation/ contemplation group. However, there were no statistically significant differences in mean experiential processes scores between the action and the precontemplation/ contemplation groups. The Cronbach alpha score for this scale was 0.92 .

\section{Processes of Change-behavioral}

A one-way ANOVA comparing the three stages of change groups on behavioral processes of change with a follow up Turkey pos hoc statistical analysis indicated that the 
action groups' mean score on behavioral processes of change was significantly higher than the mean behavioral processes of change score of the precontemplation/contemplation group, $F(2,67)=9.53, p<.01, \mathrm{ES}=0.22$. Additionally, the mean behavioral processes of change score for the preparation group was also found to be significantly higher than the mean behavioral processes of change score for the precontemplation/ contemplation group. On the other hand, there were no statistically significant differences in mean behavioral processes of change scores between the preparation and action groups. The Cronbach alpha score for this scale was found to be 0.93 .

In summary, the current study revealed that participants who rated themselves as advanced in their stages of change generally reported an increase in their self efficacy, their utilization of pros as opposed to cons and their use of behavioral processes of change when compared to experiential processes of change.

Are there differences between athletes' Stages of Change and their compliance rates, adherence rates and the discrepancy scores between athletic trainer's perceived versus actual completion rates of rehabilitation.

Three one-way ANOVA comparing the three stages of change groups on mean compliance rates, mean adherence rates and the mean discrepancy scores between athletic trainer's perceived versus actual completion rates of rehabilitation indicated that there were no statistically significant differences between the groups' mean scores on compliance rates, adherence rates and these discrepancy scores. 
Are these athletes' scores on self efficacy, decisional balance and processes of change predictors of their compliance rates and adherence rates and the discrepancy scores between athletic trainer's perceived versus actual completion rates of rehabilitation.

Three separate linear regression analyses were conducted to determine which of the independent variables (self efficacy, decisional balance- pros and cons, and processes of change- experiential and behavioral) were significant predictors of compliance rates as determined by the $\operatorname{SIRAS}^{32}$; adherence rates as determined by participants' attendance at their rehabilitation; and the discrepancy scores between athletic trainers' perceived versus actual completion rates of rehabilitation scores. None of these independent variables proved to be significant predictors of compliance, $F(5,69)=1.58, p=.179$; adherence, $F$ $(5,69)=0.85, p=.517$ and discrepancy scores between perceived versus actual completion rates of rehabilitation, $F(5,69)=1.48, p=.21$.

\section{Discussion}

Results from the current study revealed that participants who rated themselves as advanced in their stages of change generally reported an increase in their self efficacy, their utilization of pros as opposed to cons and their use of behavioral processes of change when compared to experiential processes of change. These findings supported the current study hypotheses. These results also seemed to be consistent with previous

research as Wong ${ }^{15}$ found that as individuals progressed through the stages of change they reported an increase in their self efficacy. Marcus, Rossi, Selby, Niaura and Abrams ${ }^{12}$ and Marcus, Selby, Niaura and Rossi ${ }^{13}$ all found that as individuals progressed through the stages of change they relied more heavily on experiential processes earlier in the stages and more on the behavioral processes in the later part of their stages of change. 
Lastly Marcus, Rakowski and Rossi ${ }^{17}$ showed that the pros outnumbered the cons in contemplation through maintenance stages of the stages of change.

In the current study, therefore, it appears that the use of psychological assessment based on stages of change within the injury rehabilitation context may have some validity. For example, previous research has indicated that assessing an individual's readiness for surgery would be advantageous. ${ }^{9}$ The knowledge obtained from that assessment could have been used to help determine if surgery at that point in time would be helpful or if it would be in the patient's best interest to delay the process. Similarly, by assessing athletes' psychological readiness, the athletic training staff could get an indication of which athletes are ready to commence rehabilitation. Consequently, as they (athletic trainers) become aware of athletes who are not ready for this stage of the injury recovery process suitable interventions and referrals could be made.

Athletes who have been deemed not psychologically ready for rehabilitation, (i.e. those who rated themselves in precontemplation/ contemplation stages of change groups) should be referred to a sport and exercise psychologist for the appropriate psychological interventions to be administered. Research has shown that individuals who are in the early stages of change of any behavior can benefit immensely from the application/ use of cognitive processes/ strategies. ${ }^{25}$ Accordingly, there are a number of strategies that the sport and exercise psychologist along with the help of the athletic trainer could use to help these individuals prepare for their impending rehabilitation and progress in their readiness. These practitioners can make use of some of the basic tenets of the Protection Motivation Theory for example by increasing the individual's knowledge about the rehabilitation process, helping the individual comprehend the benefits of consistently and 
efficiently participating in rehabilitation, and conversely, informing the individual of the inherent risks of not participating in rehabilitation. Furthermore, the sport and exercise psychologist may also want to develop interventions to help these individuals increase their confidence and motivation for participation in rehabilitation. Alas when athletic trainers encounter individuals who have deemed themselves psychologically ready for rehabilitation (i.e. those who rated themselves in preparation and action stages of change groups), they should introduce these individuals to some of the many behavioral strategies which research has shown to be quite effective in facilitating behavior change. Probably one of the most effective strategies that can be used is to encourage athletes to implement a system of goal setting within their rehabilitation programs as well as employing the use of self monitoring strategies to enable them to chart their own progress.

However, because an individual has been deemed psychologically ready within the context of the athletic training room environment this assessment may not be an accurate reflection of the individual outside of the athletic training room environment. Rehabilitation is not solely limited to the athletic training. Usually, these programs include an adjustment of activities of daily living in addition to involvement in home exercise and treatment regimes. As a result, if the individual is only fulfilling their athletic training room commitment to rehabilitation while ignoring the other important components this individual's progress in rehabilitation will be impeded. This hindrance could possibly lead to rehabilitation setbacks which could not only cause the athlete to question the effectiveness of their rehabilitation program but may even lead to a possible relapse in their stages of change. This situation is even more likely in the event that 
rehabilitation exercises progressively gets harder and there is a corresponding increase in pain and discomfort and a consequent increase in the length of the time one has to stay in rehabilitation.

Furthermore, athletic trainers and sport and exercise psychologists should be cautious of the possibility of relapse for those individuals who have rated themselves as psychologically ready for rehabilitation. It could be mistakenly assumed that these individuals because of their self reported stage of change are well on their way to achieving behavior change-consistent participation in their rehabilitation program. However, research has shown that even individuals who are advanced in their stages of change are susceptible to relapse. ${ }^{25}$ Action has been shown to be the least stable stage. As an individual commences their behavior change they usually experience a slight increase in their cons. ${ }^{25}$ Similarly, in rehabilitation an individual who has been deemed psychologically ready could be vulnerable to high risk situations which could possible trigger them to relapse in their stages of change and consequently their rehabilitation. Some of these possible high risk situations are inclement weather, preventing them from getting to the athletic training room. Time constraints, having to make time to study for an examination as opposed to attending rehabilitation or even low social support, being surrounded by individuals who don't value rehabilitation or have not had success in with previous rehabilitation programs could cause relapse.

The external validity of these results are impacted by the fact that $78.6 \%$ of the participants indicated that they had previous experience with rehabilitation. This previous experience may influence how an individual approaches subsequent rehabilitation sessions. It must, however, be stated that even though an athlete has already been through 
rehabilitation for a particular injury a reoccurrence of that injury can be quite a psychological setback. Consider the following situation: an athlete sustained an injury which required him/ her to attend intensive rehabilitation for a month. Upon completion of this rehabilitation program the athlete returned to the field of play. However, later in the season the athlete incurred the same injury again. It is within reason to assume that this individual's past experience in rehabilitation should dictate that he/she possess a high level of self efficacy, know how to rationalize the use of the pros versus cons of rehabilitation, and understand the advantages of using behavioral processes of change (see previous page) when compared to experiential processes if change. Yet it is quite conceivable that this individual could have lost all of the aforementioned after resustaining the injury. This could possibly explain why the current study had 34 participants in the $1^{\text {st }}$ two stages- precontemplation and contemplation even though $55.7 \%$ had previous experience.

Lastly, consideration must also be given to the fact that $52.9 \%$ of the participants sustained their injuries in the preseason. Incurring an injury in the preseason gives an individual the hope of possibly being able to return to competition, that season, depending on the severity of the injury. As a result, this individual will most likely be much more psychologically ready to participate in rehabilitation knowing that there is the chance that he/she could once again return to the field of play that season. Conversely, if the injury was suffered late in the season, psychological readiness for rehabilitation might indicate that he/she might not be able to come back to the field of play that season.

While the results of the current study seem to contradict the aforementioned as 34 participants rated themselves in the first two stages further consideration must be given to 
some of the extraneous variables which might have influenced participants rating themselves in those stages of change groups. Chief among these is that $37.1 \%$ of the participants in the study were in their freshman year of competition. These athletes could possibly have been dealing with the sometimes difficult transition from high school athletics to college athletics, the increase time commitment now required by their sport, and the increased travel associated with sport. ${ }^{26}$ Furthermore, these athletes may be also dealing with the increased demands now being required of them by their coaches.

Consequently, it is quite possible that even though some of the participants were injured in the early part of their season the weight of some of the aforementioned variables could have influenced their psychological readiness for rehabilitation.

The current study utilized a sample size of 70 participants which in relative terms within injury research context was similar to the sample size of 108 used by Wong. ${ }^{15}$ It must also be mentioned that with the exception of $\operatorname{Wong}^{15}$ none of the other samples had applied the TTM to injury rehabilitation. As noted, much of the research conducted with respect to the TTM has been used in the realm of exercise adoption. Although rehabilitation can be likened to adopting a new behavior there are many differences between both these situations. Firstly, rehabilitation programs unlike exercise adoption are not planned. Athletes usually commence rehabilitation programs after sustaining an injury. In addition, their attendance and participation in rehabilitation is required as opposed to the volunteer nature of exercise adoption. Furthermore, commencing a rehabilitation program can sometimes be quite a stressful experience for an individual especially if it is the first time an individual has experienced an injury. Furthermore, the stage of the athlete's season in which the injury has occurred and also the severity of the 
injury are factors to take into consideration with respect to an athlete's approach towards their impending rehabilitation. Consequently, it could be reasoned that with the aforementioned extraneous variables it is possible to see why the results were not identical to previous research. Furthermore, using the Health Belief Model, an individual who wants to start participating in physical activity may be motivated by the health benefits which could be derived from physical activity participation. However, for individuals about to participate in rehabilitation these benefits are not immediately recognizable especially when an individual may be experiencing some negative consequences (depression, impaired self esteem and anxiety ${ }^{3,4}$ ) as a result of the injury.

Results from the current study did not reveal any significant differences between stages of change and compliance rates, adherence rates and discrepancy scores between athletic trainer's perceived versus actual completion rates of rehabilitation programs. Consequently, none the hypotheses with respect to the aforementioned were supported. As previously mentioned, this particular research question was derived from the future research section of the Udry, Shelbourne and Gray ${ }^{9}$ manuscript. These researchers thought that an assessment of an individual's psychological readiness could possibly have an influence on compliance and adherence rates. However, no differences were found in the current study.

Perhaps one reason was that compliance rates as assessed by the SIRAS ${ }^{24}$ revealed that there were little variance in the scores obtained between participants. The researcher, because of the time he spent in the athletic training room collecting data for the current study, found that the relationship and rapport between the athletic training staff and the injured athletes was quite remarkable. This rapport appeared to stem from 
the genuine interest by the athletic trainer in the athlete's well-being. Athletes seemed to listen to whatever the training staff told them and followed all directions and instructions given to them. As a result it was not surprising that the compliance scores lacked much variance. Lastly, it could also be postulated that the athletic trainer could have completed the instrument in a similar fashion for each participant in the study.

Likewise, adherence rate scores lacked variability as most of the athletes attended rehabilitation when they were supposed to. The rapport, understanding, and education provided by the athletic training staff made it easy to see why attendance at this particular athletic training room was never a problem. Also, the fact that rehabilitation is usually mandated by coaching staffs for athletes who are injured might have played a role in the lack of variability obtained in the adherence scores. Similarly, the derived discrepancy scores also did not show much variability. It was, however, found that the athletic trainer seemed to err on the side of caution (overestimated) with respect to his predictions of the amount of time athletes would have been in rehabilitation. The researcher also postulated that this could have occurred so as to decrease the occurrence of pressure from coaches about the length of time an athlete was out. If the athletic trainer overestimated the time the athlete would have been away and the said athlete returned to play earlier not only would the athlete's coaches be happy but the athlete would be more likely to reflect positively on their rehabilitation experience. Furthermore, the athletic trainer involved in making these predictions was very knowledgeable, had ten years of experience and, therefore, had a fairly good idea of when athletes would complete rehabilitation. Moreover, the fact that $62 \%$ of the injuries sustained by participants in the study were classified by the athletic trainer as second degree with only $38.6 \%$ requiring surgery may 
have made the task of predicting the length of rehabilitation much easier. Traditionally, third degree injuries are much more difficult to predict in terms of the amount of time an athlete will be in rehabilitation; similarly, long term injuries which require surgery are likewise difficult to predict also, almost half (55.7\%) of the participants in the study were in rehabilitation for injuries they had already been in rehabilitation for. This could possibly have made the prediction process of rehabilitation much easier due to the athletic trainer's previous experience with the athlete's rehabilitation. Furthermore, given that the athletes in this athletic trainer's care seemed to comply and adhere it would stand to reason that his assessment of when they would complete their rehabilitation would also be fairly accurate. Lastly, it must also be mentioned that independent data analyses revealed that participants' level of self efficacy was not related to the athletic trainer's prediction of the amount of time the individual would have spent in rehabilitation. Research has shown self efficacy to be a very important attribute contributing to adherence and compliance to rehabilitation programs which are directly related to the amount of time an individual will spend in rehabilitation. As a result, it was quite surprising that no relationship was found.

Lastly, results revealed that none of the variables- self efficacy, pros and cons, and processes of change were significant predictors of athletes' adherence rates, compliance rates and the discrepancy scores between perceived versus actual completion rates of rehabilitation programs. This research question reflected the exploratory nature of the study since previous research has not been done in this area. The researcher believed that self efficacy would have been revealed as predictor of either adherence rates or compliance rates. Self efficacy is an important construct which has been shown to be 
predictive of behavior because once an individual believes that he/she can perform a behavior the likelihood of doing so is very much increased. However, given a lack of variability in the criteria scores in the multiple regression analyses performed, it is not surprising that self efficacy (or the other predictor variables) did not statistically contribute to explaining the differences in these athletes' compliance and adherence scores.

In conclusion, it would appear that the stages of change model provides a viable conceptual framework for helping athletic trainers understand their clients' self efficacy, utilization of pros versus cons aspects of decisional balance in addition to their use of behavioral as opposed to experiential processes of change during different phases of the rehabilitation process. Future research perhaps should be directed towards using a different method of assessing compliance and adherence to determine if a relationship does exist between psychological readiness and compliance and adherence. Furthermore, a qualitative study could be conducted to ascertain the differences in athletic trainers' perception between those individuals who are deemed psychological as opposed those who are deemed not psychologically ready for rehabilitation. Additionally, future research in this area could possibly include an assessment of individual's anxiety, depression and mood levels. ${ }^{11}$ Given the context of injury rehabilitation it is possibly that these factors could also influence psychological readiness. Another limitation of the current study which could be addressed in future research is taking into consideration the variability of injuries included in the study. The current study included all injury types while it is quite possible that athletes' psychological readiness for rehabilitation could be influenced by the type of injury they have sustained. Lastly, the current study could be 
continued in the hopes of obtaining a larger sample size to further validate the stages of change with respect to injury rehabilitation. 


\section{REFERENCES}

1. Fisher AC, Domm MA., Wuest DA. Adherence to sports injury rehabilitation programs. The Physician and Sportsmedicine. 1988; 16: 47-52.

2. Heil J. Psychology of Sport Injury. Roanoke, VA: Human Kinetics Publishers; 1993

3. Crossman J. Psychological factors and athletic injury. Journal of Sports Medicine and Physical Fitness.1985; 25: 151-154.

4. Weiss MR, Troxel RK. Psychology of the injured athlete. Athletic Training. 1986; 21: 104-109.

5. Weise DM, Weiss MR. Psychological rehabilitation and physical injury: Implications for the sportsmedicine team. The Sport Psychologist. 1987; 1:318330 .

6. Brewer BW, Van Raalte JL, Cornelius AE, Petipas AJ, Sklar, JH, Pohlman MH, Krushell RJ, Ditmar TD. Psychological factors, rehabilitation adherence and rehabilitation outcome for anterior cruciate ligament reconstruction. Rehabilitation Psychology. 2000; 20-37

7. Brewer BW. Adherence to sport injury rehabilitation programs. Journal of Applied Sport psychology. 1998; 10: 70-82.

8. Daly JM, Brewer BW, Van Raalte, JL, Petipas AJ, Sklar JH. Cognitive appraisal emotional adjustment and adherence to rehabilitation following knee surgery. Journal of Sport Rehabilitation.1995; 4: 23-30.

9. Udry E, Shelbourne KD, Gray T. Psychological readiness for anterior cruciate ligament surgery: Describing and comparing the adolescent and adult experiences. Journal of Athletic Training. 2003; 38: 167-171.

10. Prochaska JO, DiClemente CC. Stages and processes of self-change in smoking: Toward an integrative model of change. Journal of Consulting \& Clinical Psychology. 1983; 51: 390-395.

11. Herrick AB, Stone WJ, Mettler MM. Stages of change, decisional balance, and self efficacy across four health behaviors in a worksite environment. American Journal of Health Promotions. 1997; 12: 49-56.

12. Marcus BH, Rossi JS, Selby VC, Niaura RS, Abrams DB. Process of change questionnaire. Health Psychology.1992; 11: 386-395. 
13. Marcus BH, Selby VC, Niaura, RS, Rossi JS. Self efficacy and the stages of exercise behavior change. Research Quarterly for Exercise and Sport. 1992; 63: 60-66.

14. Bandura A. Self efficacy: Towards a unifying theory of behavior change. Psychological Reviews. 1977; 84: 191-215.

15. Wong IE. Injury Rehabilitation Behavior: An Investigation of Stages and Processes of Change in the Athlete-Therapist Relationship. Unpublished master's thesis, University of Oregon. 1998.

16. Janis JL, Mann L. Decision Making: A Psychological Analysis of Conflict, Choice and Commitment. New York: Free Press; 1977

17. Marcus BH, Rakowski W, Rossi JS. Assessing motivational readiness and decision making for exercise. Health Psychology.1992; 11: 257-261.

18. Prochaska JO, Velicer WF, Guadagnoli E, Rossi JS, Di Clemente CC. Patterns of change: Dynamic typology applied to smoking cessation. Multivariate Behavioral Research. 1992; 26: 83-107.

19. Leffingwell T, Rider S, Williams J. Application of the transtheoretical model to psychological skills training. The Sport Psychologist. 2001; 15: 168-183.

20. Cardinal BJ. The stages of exercise scale and stages of exercise behavior in female adults. Journal of Sports Medicine and Physical Fitness. 1995; 35: 87-92.

21. Marcus BH, Owen N. Motivational readiness, self efficacy, and decision making. Journal of Applied Social Psychology. 1992; 22:3-16.

22. O'Hea EL, Wood KB, Brantley PJ. The transtheoretical model: Gender differences across 3 health behaviors. American Journal of Health Behaviors. 2003; 27:645-656.

23. Taylor AH, May S. Threat and coping appraisal as determinants of compliance with sports injury rehabilitation: An application of protection motivation theory. Journal of Sports Sciences. 1996; 14:471-482.

24. Brewer BW, Van Raalte JL, Petipas AJ, Sklar JH, Pohlman MH, Krushell RJ, Ditmar TD, Daly JM, WEinstock J. Preliminary psychometric evaluation of a measure of adherence to clinic-based sport injury rehabilitation. Physical Therapy in Sport. 2000; 1: 68-74.

25. Marcus BH, Forsyth AH. Motivating people to be physically active. Champaign, IL: Human Kinetics. 
26. Etzel EF, Ferrante AP Pinkney JW. Counseling college studentathletes: Issues and Interventions. Morgantown, WV: Fitness Information Technology; 1996. 


\section{Table 1}

Demographic Characteristics of Injured Athletes $(N=70)$.

\begin{tabular}{llll}
\hline$\%$ & $M$ & $S D$
\end{tabular}

Gender

Male

Female

Varsity Sport

Men's Soccer

Women's Soccer

Wrestling

Baseball

Swimming

Academic Year

Freshman

Sophomore

Junior

Senior

When did injury occur?

Pre-season

Beginning of Season

Mid Season

End of Season

Previously attended rehabilitation

Yes

No

Previously attended rehabilitation

for current injury

Yes

No

Previously attended rehabilitation

for another injury

$$
\text { Yes }
$$

No

Experiencing stress due to injury*

Injury difficult to deal with*

Rating of past rehabilitation experience*

* Note- on a scale of 1-5
38.5

31.5

12.8

7.1

4.3

37.1

30

21.4

11.4

52.9

28.6

8.6

10

78.6

21.4

55

15

$65.7 \quad 46$

$32.9 \quad 23$

3.39

.91

$3.14 \quad .95$

$3.96 \quad .86$ 
Table 2

Descriptive Statistics for three Stages of Change Groups for self efficacy, decisional balance, processes of change, compliance rates, adherence rates and discrepancy between athletic trainer's perceived versus actual completion rates of rehabilitation scores..

\begin{tabular}{|c|c|c|c|c|c|c|}
\hline \multirow[b]{4}{*}{ Athletes Psychological Readiness } & \multicolumn{4}{|c|}{ All respondents $(N=70)$} & & \\
\hline & \multicolumn{2}{|c|}{ Precontemplation/contemplation } & \multirow{2}{*}{\multicolumn{2}{|c|}{$\begin{array}{l}\text { Preparation } \\
\qquad(N=28)\end{array}$}} & \multirow{2}{*}{\multicolumn{2}{|c|}{$\begin{array}{l}\text { Action } \\
(N=18)\end{array}$}} \\
\hline & $(N=18)$ & $(N=16)$ & & & & \\
\hline & $M$ & $S D$ & $M$ & $S D$ & $M$ & $S D$ \\
\hline Self Efficacy & 15.75 & 8.06 & 23.46 & 3.37 & 24.11 & 2.95 \\
\hline \multicolumn{7}{|l|}{ Decisional Balance } \\
\hline Pros & 24.29 & 8.58 & 33.86 & 6.50 & 32.83 & 5.70 \\
\hline Cons & 19.67 & 6.99 & 12.68 & 3.29 & 14.17 & 4.57 \\
\hline \multicolumn{7}{|l|}{ Processes of Change } \\
\hline Behavioral & 36.17 & 13.29 & 53.00 & 13.10 & 49.11 & 10.03 \\
\hline Experiential & 57.96 & 8.69 & 40.04 & 12.64 & 51.06 & 9.80 \\
\hline \multicolumn{7}{|l|}{ Athletic Training Ratings } \\
\hline Compliance Rates & 11.75 & 1.45 & 11.07 & 2.59 & 11.72 & 1.95 \\
\hline Adherence Rates & 97.88 & 3.47 & 96.49 & 5.95 & 97.35 & 4.33 \\
\hline Discrepancy Scores & 22.04 & 22.31 & 19.18 & 22.93 & 20.46 & 26.80 \\
\hline
\end{tabular}




\section{APPENDIX A}

Athlete's Demographic Questionnaire 


\section{ATHLETE'S DEMOGRAHIC QUESTIONNNAIRE}

Name

1. Gender: $\mathrm{M}$ F

2. Varsity Sport

3. Academic year: Freshman Sophomore

Junior

Senior

4. When did the injury occur?

Pre- Season Beginning of the Season Mid Season End of the Season

Rate the following statements using the scale provided

5. I am experiencing stress due to my injury

$\begin{array}{lllll}1 & 2 & 3 & 4 & 5\end{array}$

6. My injury is difficult to deal with

$\begin{array}{lllll}1 & 2 & 3 & 4 & 5\end{array}$

7. Have you attended rehabilitation before? Yes No

8. Did you attend rehabilitation for this previous injury? Yes No

9. Did you attend rehabilitation for other injuries? Yes No

10. Rate your past rehabilitation experience using the below scale

$\begin{array}{llllll}\text { Very negative } 1 & 2 & 3 & 4 & 5 & \text { Very Positive }\end{array}$


APPENDIX B

Athletic Trainers' Demographic Questionnaire 


\section{ATHLETIC TRAINER'S DEMOGRAHIC QUESTIONNNAIRE}

1. How long have you been involved in athletic training?

2. How long have you been at the current institution?

3. On what date did this athlete sustain the injury for which he/ she is being treated

4. What degree of severity in your professional opinion is this athlete's injury? Second Degree Third Degree

5. Did this injury require surgery?

Yes No

6. How many days do you expect this athlete to rehabilitate this injury before returning to practice/ competition? 
APPENDIX C

Stage of Change Instrument 


\section{STAGES OF CHANGE INSTRUMENT}

Please CIRCLE the number on the ladder that best describes your injury rehabilitation behavior.

"Regular rehabilitation" means attending rehabilitation the number of times your athletic trainer recommends, putting forth adequate effort, and completing any home exercises given.

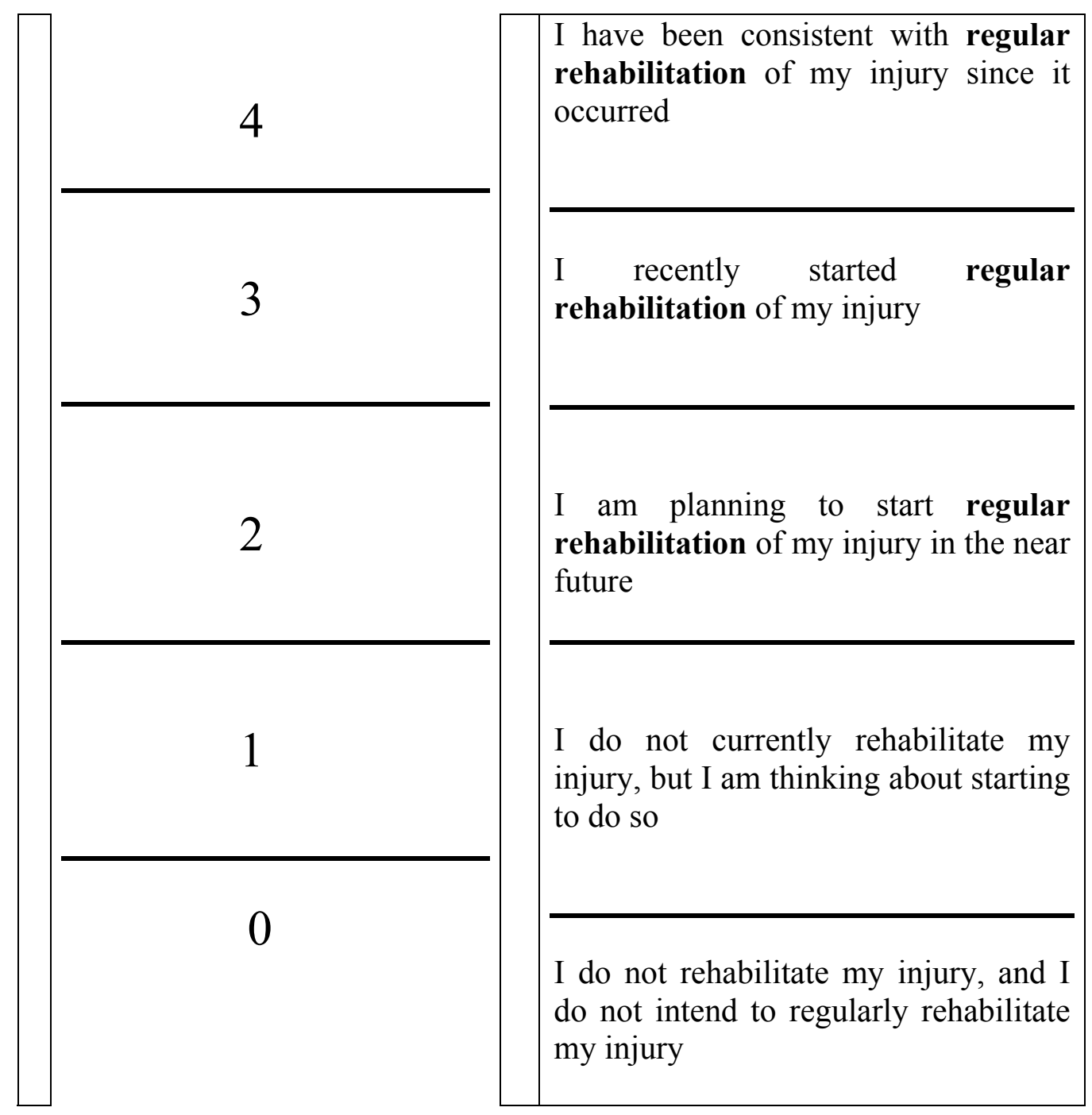


APPENDIX D

Injury Rehabilitation Survey 
INJURY REHABILITATION SURVEY

\section{PART 1}

Please CIRCLE the number that best represents how you feel using the scale below

$\begin{array}{lllllllll}\begin{array}{l}\text { Strongly (SD) } \\ \text { Disagree (SD) }\end{array} & 1 & 2 & 3 & 4 & 5 & 6 & 7 & \begin{array}{l}\text { Strongly } \\ \text { agree (SA) }\end{array}\end{array}$

$* * \mathbf{R P}=$ rehabilitation program

\begin{tabular}{|c|c|c|c|c|c|c|c|c|}
\hline & & & & & & & & \\
\hline 1 & $\begin{array}{l}\text { My recovery from injury may be hindered if I do not complete the } \\
\text { rehabilitation program (RP). }\end{array}$ & 1 & 2 & 3 & 4 & 5 & 6 & 7 \\
\hline 2 & In order to prevent a recurrence of this injury, RP is essential & 1 & 2 & 3 & 4 & 5 & 6 & 7 \\
\hline 3 & $\begin{array}{l}\text { The way to prevent my injury from worsening will be to } \\
\text { follow my RP. }\end{array}$ & 1 & 2 & 3 & 4 & 5 & 6 & 7 \\
\hline 4 & $\begin{array}{l}\text { A successful and lasting recovery may not be possible if I do } \\
\text { not complete my RP. }\end{array}$ & 1 & 2 & 3 & 4 & 5 & 6 & 7 \\
\hline 5 & $\begin{array}{l}\text { I am making it more likely that I will not be re-injured by } \\
\text { not doing what my RP involves. }\end{array}$ & 1 & 2 & 3 & 4 & 5 & 6 & 7 \\
\hline 6 & $\begin{array}{l}\text { The RP designed for me will ensure my complete recovery } \\
\text { from this injury. }\end{array}$ & 1 & 2 & 3 & 4 & 5 & 6 & 7 \\
\hline 7 & $\begin{array}{l}\text { Completion of my RP will guarantee that I recover from my } \\
\text { injury. }\end{array}$ & 1 & 2 & 3 & 4 & 5 & 6 & 7 \\
\hline 8 & $\begin{array}{l}\text { Following the advice that I have been given will have a very } \\
\text { large impact upon how quickly I recover from this injury. }\end{array}$ & 1 & 2 & 3 & 4 & 5 & 6 & 7 \\
\hline 9 & I have absolute faith in the effectiveness of my RP. & 1 & 2 & 3 & 4 & 5 & 6 & 7 \\
\hline 10 & $\begin{array}{l}\text { I a very capable of successfully completing all aspects of my } \\
\text { RP, even if it involves being less active or doing something } \\
\text { which may be uncomfortable. }\end{array}$ & 1 & 2 & 3 & 4 & 5 & 6 & 7 \\
\hline 11 & $\begin{array}{l}\text { I will be able to stick to my RP even though it may include } \\
\text { activities which I do not enjoy. }\end{array}$ & 1 & 2 & 3 & 4 & 5 & 6 & 7 \\
\hline 12 & $\begin{array}{l}\text { I will have no serious difficulty in following the instructions } \\
\text { of my RP. }\end{array}$ & 1 & 2 & 3 & 4 & 5 & 6 & 7 \\
\hline 13 & $\begin{array}{l}\text { I believe that I will stick with my RP despite any difficulties } \\
\text { I may encounter. }\end{array}$ & 1 & 2 & 3 & 4 & 5 & 6 & 7 \\
\hline 14 & Being fully recovered is important to me. & 1 & 2 & 3 & 4 & 5 & 6 & 7 \\
\hline 15 & As injuries go, mine is serious. & 1 & 2 & 3 & 4 & 5 & 6 & 7 \\
\hline 16 & I see this injury as a serious threat to my sport involvement. & 1 & 2 & 3 & 4 & 5 & 6 & 7 \\
\hline 17 & $\begin{array}{l}\text { I fear that this injury will affect my long term sport } \\
\text { involvement. }\end{array}$ & 1 & 2 & 3 & 4 & 5 & 6 & 7 \\
\hline 18 & This injury is too serious to not follow medical advice. & 1 & 2 & 3 & 4 & 5 & 6 & 7 \\
\hline 19 & $\begin{array}{l}\text { Injuries like this are minor interruptions to my sport } \\
\text { involvement. }\end{array}$ & 1 & 2 & 3 & 4 & 5 & 6 & 7 \\
\hline
\end{tabular}




\section{PART 2}

Please CIRCLE the number which best represents how you feel using the scale below.

$\begin{array}{lllllll}\text { Not at all important } & 1 & 2 & 3 & 4 & 5 & \text { Extremely important }\end{array}$

Not at all Extremely

\begin{tabular}{|c|c|c|c|c|c|c|}
\hline 20 & $\begin{array}{l}\text { I would have more energy for my friends if I rehabilitated } \\
\text { regularly }\end{array}$ & 1 & 2 & 3 & 4 & 5 \\
\hline 21 & Regular rehabilitation will help me relieve tension. & 1 & 2 & 3 & 4 & 5 \\
\hline 22 & I will feel more confident if I rehabilitated regularly & 1 & 2 & 3 & 4 & 5 \\
\hline 23 & $\begin{array}{l}\text { I will feel good about myself if I kept my commitment to } \\
\text { rehabilitate regularly }\end{array}$ & 1 & 2 & 3 & 4 & 5 \\
\hline 24 & Regular rehabilitation will take too much of time & 1 & 2 & 3 & 4 & 5 \\
\hline 25 & $\begin{array}{l}\text { I will have less time for my teammates and friends if I } \\
\text { rehabilitated regularly }\end{array}$ & 1 & 2 & 3 & 4 & 5 \\
\hline 26 & $\begin{array}{l}\text { At the time when I am scheduled to attend rehabilitation I am too } \\
\text { exhausted to do so. }\end{array}$ & 1 & 2 & 3 & 4 & 5 \\
\hline 27 & $\begin{array}{l}\text { I think I would be too tired to do my daily work after } \\
\text { rehabilitating. }\end{array}$ & 1 & 2 & 3 & 4 & 5 \\
\hline 28 & $\begin{array}{l}\text { I would find it difficult to find a rehabilitation activity that I enjoy } \\
\text { that is not affected by my class schedule }\end{array}$ & 1 & 2 & 3 & 4 & 5 \\
\hline 29 & I would like my body better if I rehabilitated regularly & 1 & 2 & 3 & 4 & 5 \\
\hline 30 & $\begin{array}{l}\text { It would be easier for me to perform routine physical tasks if I } \\
\text { rehabilitated regularly }\end{array}$ & 1 & 2 & 3 & 4 & 5 \\
\hline 31 & I would feel less stressed if I rehabilitated regularly & 1 & 2 & 3 & 4 & 5 \\
\hline 32 & $\begin{array}{l}\text { I feel uncomfortable with myself if I rehabilitate because my heart } \\
\text { beats very fast }\end{array}$ & 1 & 2 & 3 & 4 & 5 \\
\hline 33 & $\begin{array}{l}\text { I would feel more comfortable with my body if I rehabilitated } \\
\text { regularly }\end{array}$ & 1 & 2 & 3 & 4 & 5 \\
\hline 34 & $\begin{array}{l}\text { Regular rehabilitation would help me have a positive outlook on } \\
\text { life }\end{array}$ & 1 & 2 & 3 & 4 & 5 \\
\hline 35 & I would sleep more & 1 & 2 & 3 & 4 & 5 \\
\hline
\end{tabular}

\section{PART 3}

Please CIRCLE the number which best reflects how frequently the following events occur using the scale below.

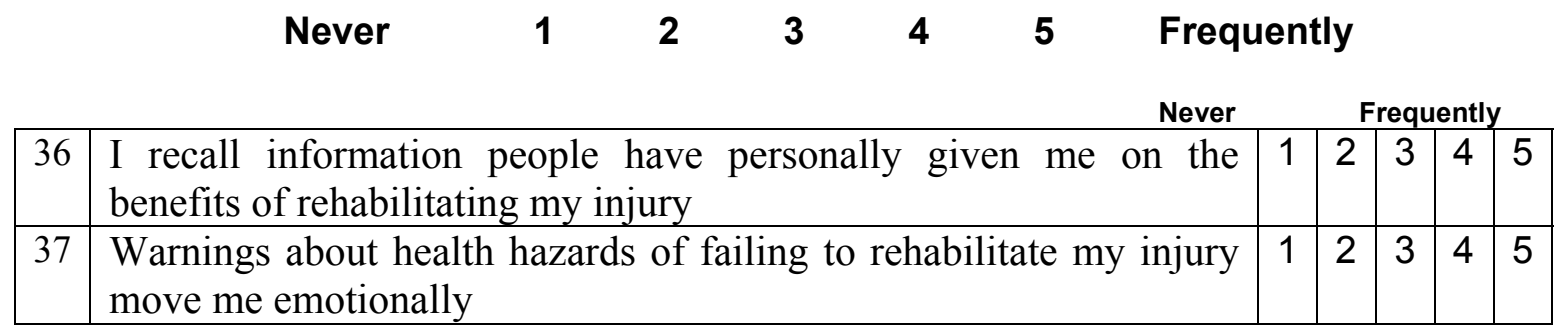




\begin{tabular}{|c|c|c|c|c|c|c|}
\hline 38 & $\begin{array}{l}\text { I feel I would be a better role model for others if I rehabilitate my } \\
\text { injury regularly }\end{array}$ & 1 & 2 & 3 & 4 & 5 \\
\hline 39 & $\begin{array}{l}\text { I am considering the idea that rehabilitating my injury regularly } \\
\text { would make me a happier person to be around }\end{array}$ & 1 & 2 & 3 & 4 & 5 \\
\hline 40 & $\begin{array}{l}\text { find society changing in ways that make it easier for people to } \\
\text { ehabilitate their injuries }\end{array}$ & 1 & 2 & 3 & 4 & 5 \\
\hline 41 & $\begin{array}{l}\text { Instead of viewing rehab as simply another task to get out of the } \\
\text { way, I try to use it as my special time to relax and recover from the } \\
\text { day's worries }\end{array}$ & 1 & 2 & 3 & 4 & 5 \\
\hline 42 & ne on whom I can depend when I a having problems & 1 & 2 & 3 & 4 & 5 \\
\hline 43 & $\begin{array}{l}\text { I do something nice for myself when I make efforts to rehabilitate } \\
\text { my injury }\end{array}$ & 1 & 2 & 3 & 4 & 5 \\
\hline 44 & $\begin{array}{l}\text { I tell myself that if I try hard enough, I can continue my } \\
\text { rehabilitation }\end{array}$ & 1 & 2 & 3 & 4 & 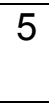 \\
\hline 45 & ound my room to remind me to rehabilitate my injury & 1 & 2 & 3 & 4 & 5 \\
\hline 46 & habilitating my injury in an effort to learn & 1 & 2 & 3 & 4 & \\
\hline 47 & nally to warnings about failing to rehabilitate my & 1 & 2 & 3 & 4 & 5 \\
\hline 48 & my injury affects those & 1 & 2 & 3 & 4 & 5 \\
\hline 49 & on I will be if I continue to rehabilitate & 1 & 2 & 3 & 4 & 5 \\
\hline 50 & $\begin{array}{l}\text { I am aware of more and more people encouraging me to } \\
\text { rehabilitate my injury }\end{array}$ & 1 & 2 & 3 & 4 & 5 \\
\hline 51 & If rehabilitate my injury because I & 1 & 2 & 3 & 4 & 5 \\
\hline 52 & my & 1 & 2 & 3 & 4 & 5 \\
\hline 53 & $\begin{array}{l}\text { nyself rather than setting myself up } \\
\text { ch }\end{array}$ & 1 & 2 & 3 & 4 & 5 \\
\hline 54 & & 1 & 2 & 3 & 4 & \\
\hline 55 & ght & 1 & 2 & 3 & 4 & \\
\hline 56 & ehabilitate & 1 & 2 & 3 & 4 & 5 \\
\hline 57 & $\begin{array}{l}\text { Dramatic portrayals of the failure to rehabilitate my injury move } \\
\text { me emotionally }\end{array}$ & 1 & 2 & 3 & 4 & 5 \\
\hline 58 & $\begin{array}{l}\text { others to rehabilitate their } \\
\text { ly }\end{array}$ & 1 & 2 & 3 & 4 & 5 \\
\hline 59 & I ge & 1 & 2 & 3 & 4 & 5 \\
\hline 60 & $\begin{array}{l}\text { ches and teammates are encouraging } \\
\text { e their injuries }\end{array}$ & 1 & 2 & 3 & 4 & 5 \\
\hline 61 & When I am feeling tense, I find rehab a good way to relieve my & 1 & 2 & 3 & 4 & 5 \\
\hline
\end{tabular}




\begin{tabular}{|c|l|l|l|l|l|l|}
\hline 62 & $\begin{array}{l}\text { I have someone who provides feedback about my injury } \\
\text { rehabilitation }\end{array}$ & 1 & 2 & 3 & 4 & 5 \\
\hline 63 & $\begin{array}{l}\text { When I rehabilitate my injury, I tell myself that I am being good to } \\
\text { myself for taking care of my body in this way }\end{array}$ & 1 & 2 & 3 & 4 & 5 \\
\hline 64 & $\begin{array}{l}\text { I tell myself I a able to continue rehabilitating my injury if I want } \\
\text { to }\end{array}$ & 1 & 2 & 3 & 4 & 5 \\
\hline 65 & $\begin{array}{l}\text { I keep things around my room that remind me to rehabilitate my } \\
\text { injury }\end{array}$ & 1 & 2 & 3 & 4 & 5 \\
\hline
\end{tabular}


APPENDIX E

Sport Injury Rehabilitation Adherence Scale 


\section{SPORT INJURY REHABILITATION ADHERENCE SCALE}

1. Circle the number that best indicated that the intensity with which this patient completes the rehabilitation exercises during their appointments.

$\begin{array}{lllllll}\text { Minimum effort } & 1 & 2 & 3 & 4 & 5 & \text { Maximum effort }\end{array}$

2. How frequently did this patient follow instructions and advice (circle)?

$\begin{array}{lllllll}\text { Minimum effort } & 1 & 2 & 3 & 4 & 5 & \text { Maximum effort }\end{array}$

3. How receptive was this patient to changes in the rehabilitation program (circle)?

$\begin{array}{lllllll}\text { Minimum effort } & 1 & 2 & 3 & 4 & 5 & \text { Maximum effort }\end{array}$

4. How long (in days) did this athlete take to rehabilitate this injury before returning to practice/ competition?

5. Rate this athlete using the scale below on he/ she meeting/ exceeding your predictions about being released from rehabilitation.

$\begin{array}{lllll}1 & 2 & 3 & 4 & 5\end{array}$


APPENDIX F

IRB Approval Letter 


\section{APPENDIX G}

Permission Responses to Use Measures 
APPENDIX $\mathrm{H}$

Health Belief Model 
Figure 1

The Health Belief Model ${ }^{28}$
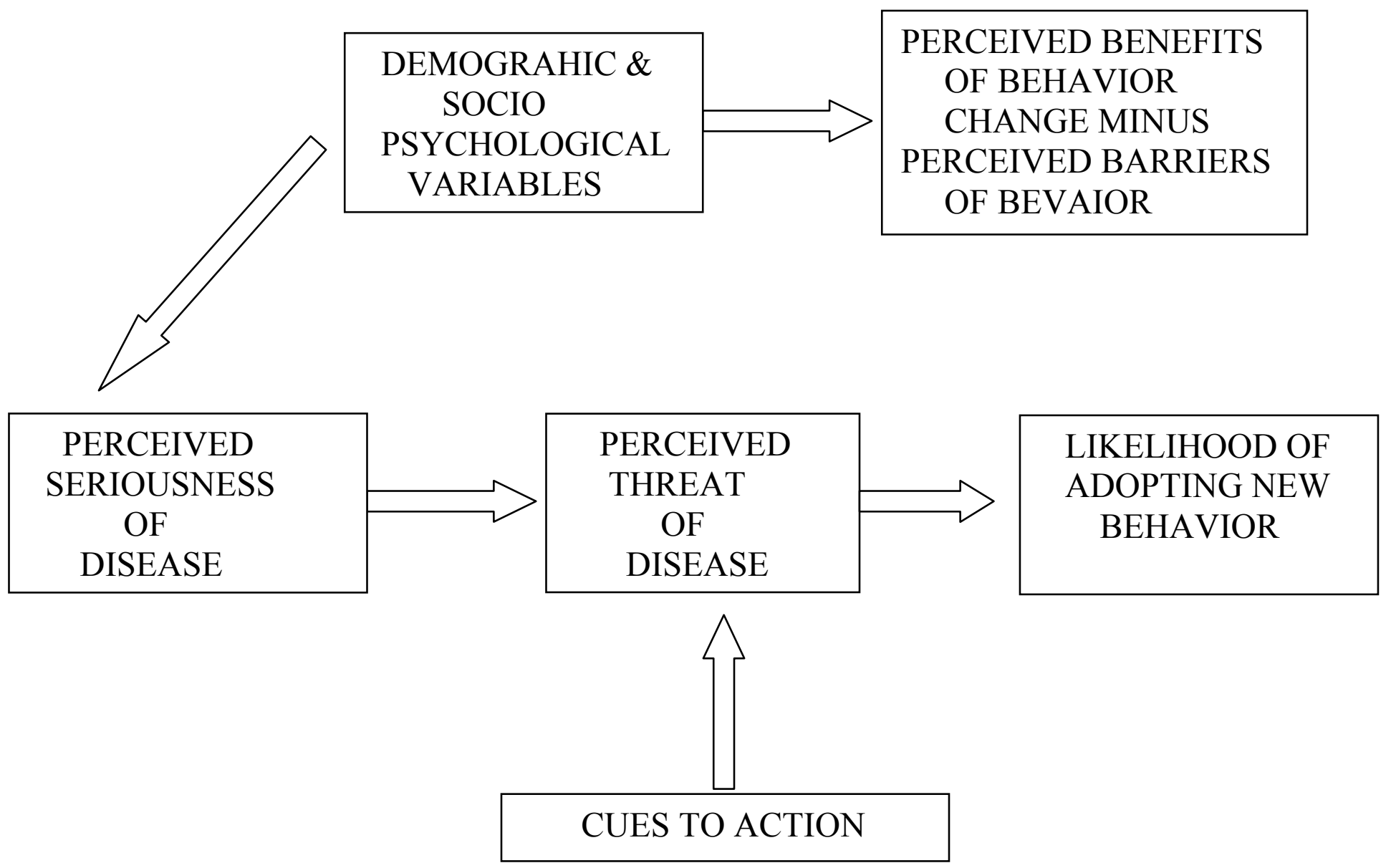


\section{APPENDIX I}

Theory of Reasoned Action 
Figure 2

Theory of Reasoned Action ${ }^{33}$
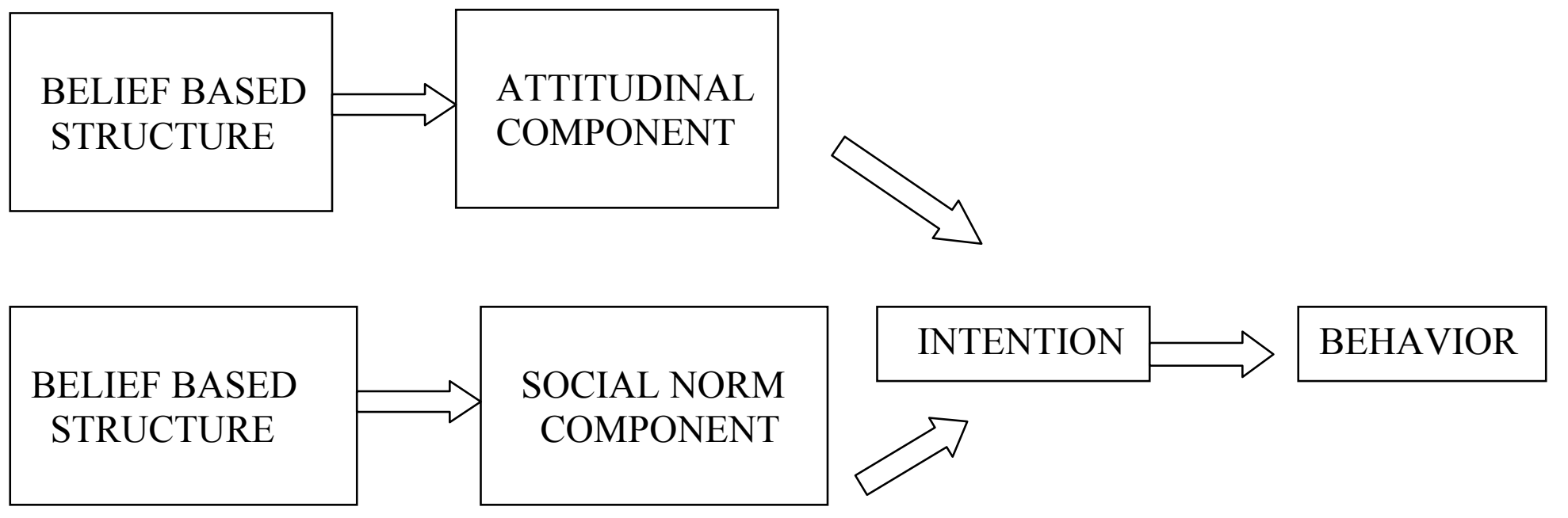


\section{APPENDIX J}

Theory of Planned Behavior 
Figure 3

Theory of Planned Behavior ${ }^{34}$
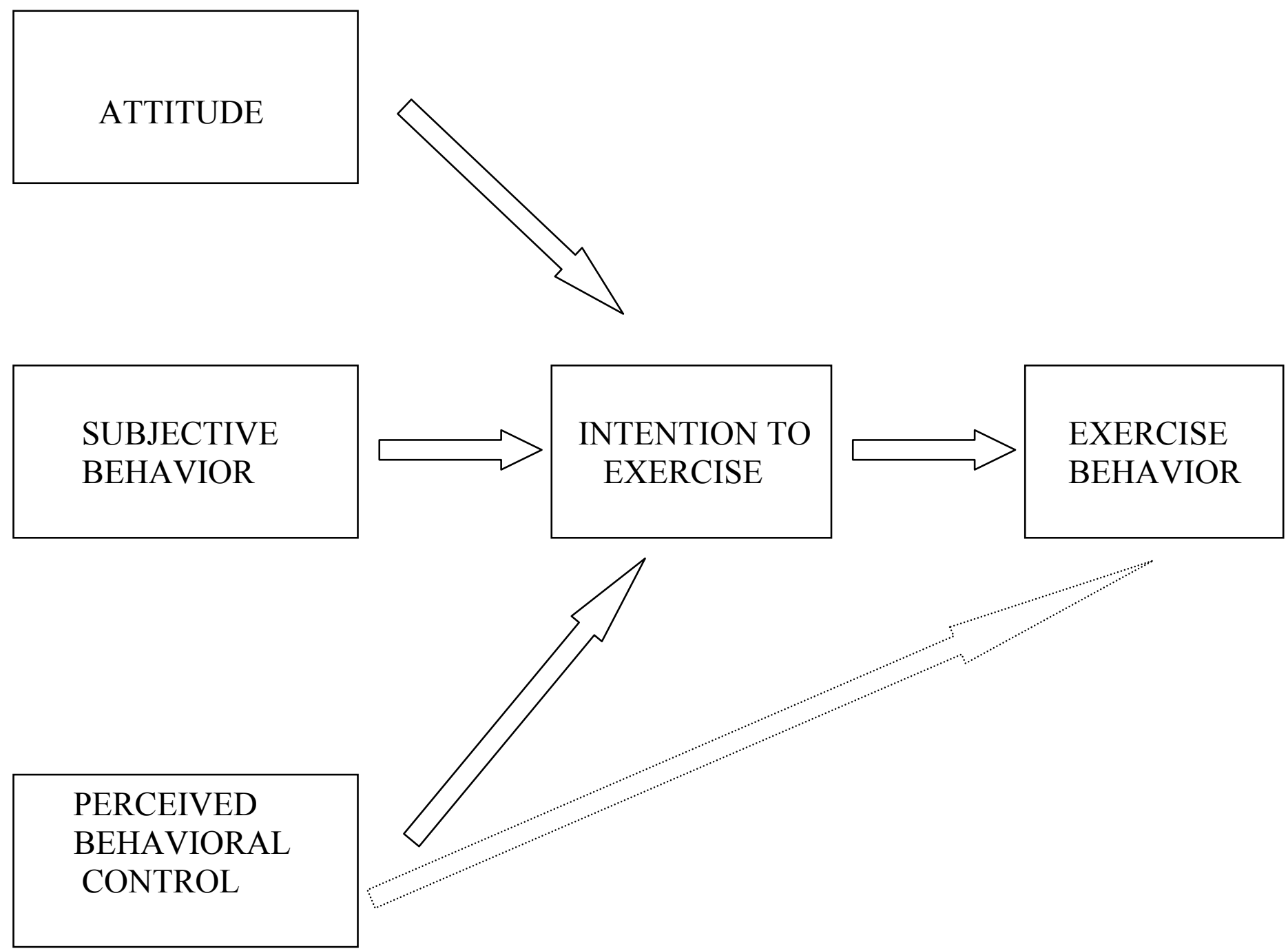

PERCEIVED BEHAVIORAL

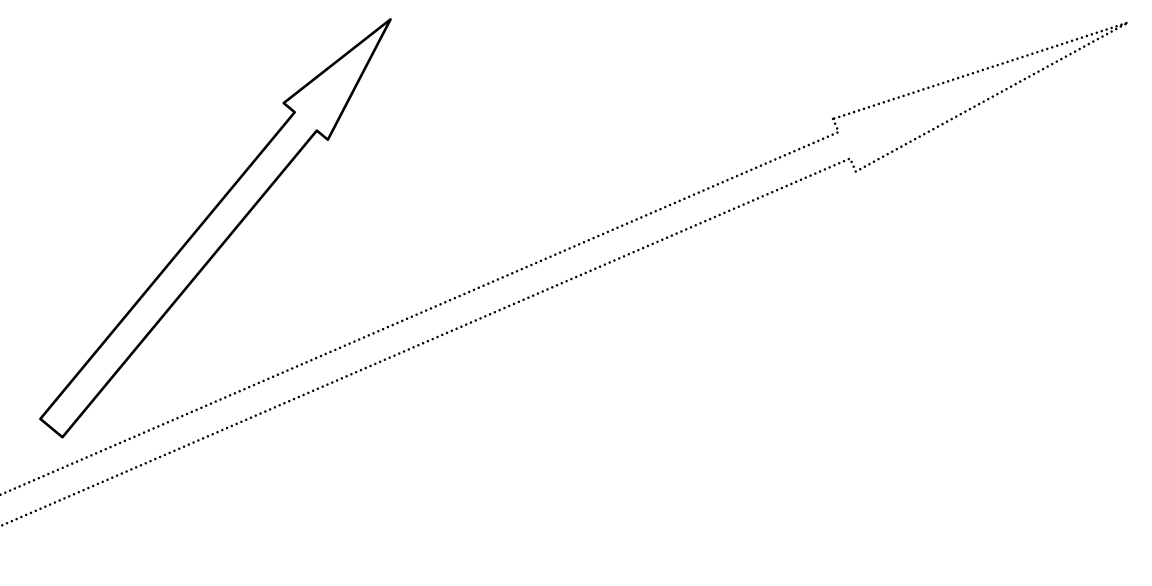


APPENDIX K

Decision Making Model 
Figure 4

Decision Making Model ${ }^{39}$

\begin{tabular}{|c|}
\hline PERCEIVED \\
BENEFITS \\
OF \\
BEHAVIOR \\
\hline
\end{tabular}

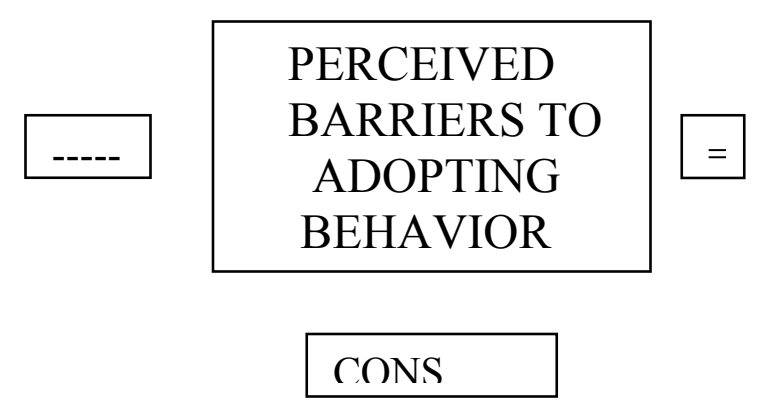

LIKELIHOOD OF ADOPTING BEHAVIOR

PROS 


\section{APPENDIX L}

Protection Motivation Theory 
Figure 5

Protection Motivation Theory ${ }^{42}$

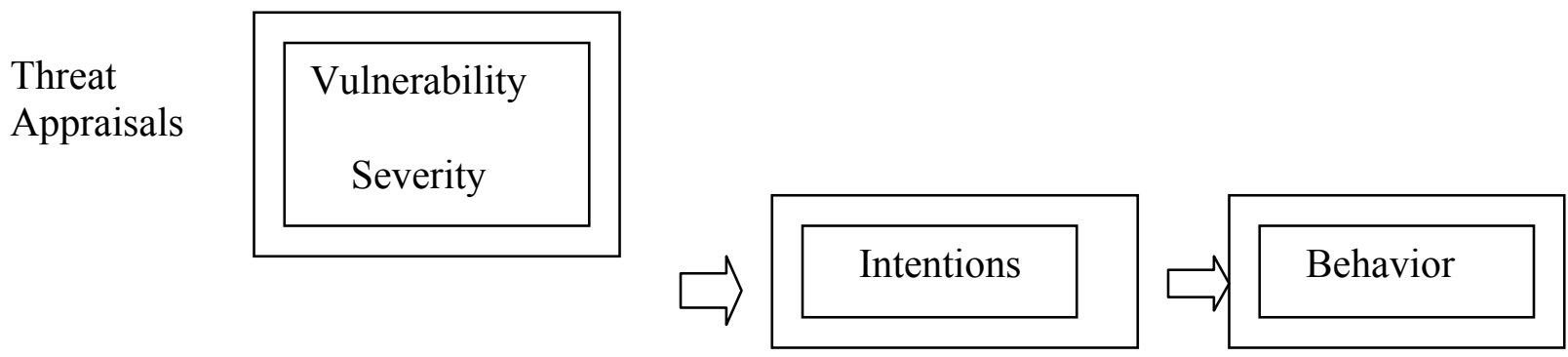

\begin{tabular}{l|l|}
\begin{tabular}{l|l} 
Coping \\
Appraisals
\end{tabular} & $\begin{array}{l}\text { Self-efficacy } \\
\text { Response efficacy }\end{array}$ \\
\hline
\end{tabular}




\section{APPENDIX M}

Transtheoretical Model 
Figure 6

Transtheoretical Model ${ }^{45}$

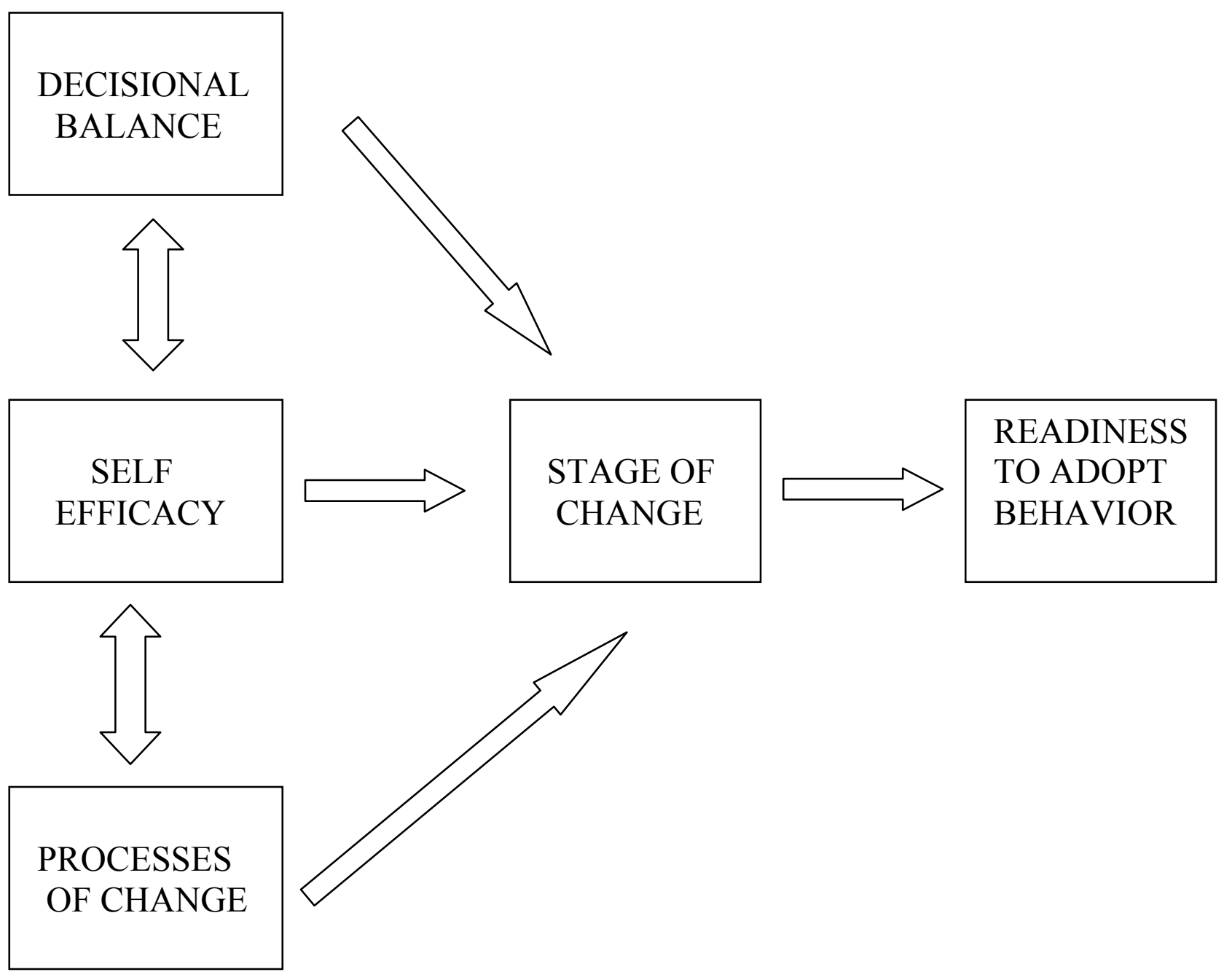




\section{REVIEW OF LITERATURE \\ Introduction}

This section of the paper will introduce the concepts of injured student athletes and the psychological ramifications which they experienced upon sustaining an injury. Additionally, emphasis will also be placed on exploring the psychological readiness of these individuals to embark on rehabilitation programs. Furthermore, because embarking on rehabilitation programs has been likened to a behavior change a number of theories with respect to behavior change will also be looked at. Lastly, factors which influence adherence to rehabilitation programs will also be discussed.

\section{Injured Student athletes}

The student athlete population present on campuses across the country has steadily risen over the past ten year. ${ }^{1}$ Furthermore, with the increased popularity of collegiate athletics these student athletes have now found themselves more in the limelight than ever before. But what usually goes unnoticed, and even unmentioned, is that these student athletes are faced with and have to overcome many of the same challenges faced by non student athletes. ${ }^{2}$ Among these challenges are having to make the social adjustment to college life and increased academic pressure and independence. ${ }^{3}$ Student athletes, also have to acclimatize themselves to playing at a much higher level than they were accustomed to in high school, in addition to an increased time commitment their sport now requires. ${ }^{3}$ Furthermore, these new student athletes also have to deal with the increased amount of travel associated with collegiate athletics, and the corresponding time spent away from the classroom. ${ }^{3}$ Thus, these student athletes are essential balancing the roles of being both a student and an athlete. ${ }^{4}$ 
These student athletes, for the most part, have been able to successfully balance both of these demands. ${ }^{3}$ However, this population is considerably more at risk to experiencing additional challenges. Among these challenges are the pressures associated with performing, lack of time to devote to their academic needs, and professors who are not very forgiving with respect to the amount of time spent away from the classroom due to athletic commitments. These factors and those mentioned previously are thought to act in unison to increase the stress levels experienced by student athletes. ${ }^{3}$ Furthermore, Etzel $^{5}$ reported that student athletes perceive themselves to experience greater amounts of stress in comparison to their non athletic counterparts. These increased stress levels have been postulated to predispose student athletes to suffering athletic injuries. ${ }^{6}$

Bramwell, Masuda, Wagner, and Holmes ${ }^{7}$ were among the first to explore to effects of life stress on injury rates of collegiate athletes. This study employed the use of 79 football players over a two-year period. Results revealed that participants, who were experiencing greater amount of changes, were found to have increased stress levels in addition to sustaining a greater number of athletic injuries. Kerr and Minden ${ }^{8}$ using elite female gymnasts also looked at the relationship between stress and injury occurrence. Results from this study supported the aforementioned study because it was found athletes perceived their stressful life situations to be significantly related to the number of injured they incurred in addition to the severity of their injuries. Andersen and Williams ${ }^{6}$ using the aforementioned studies, in addition to the existing literature, further corroborated the claim that relationship does in fact exist between stress and injury occurrence by developing the stress injury model. This model revolved around "cognitive, physiological, attentional, behavioral, intrapersonal, social and stress history variables 
(Andersen \& Williams ${ }^{6}$ p. 294). The use of this model has become quite popular with respect to the "prediction and prevention of stress related injuries" (Andersen \& Williams ${ }^{6}$ p. 294). Consequently, sport medicine and sport psychology professionals alike have began to recognize that stressful life events are particularly related to the occurrence of athletic injuries.

These athletic injuries, although occurring as a result of stressful situations have been found to vary in severity from very mild to severe. Athletic injuries not only lead to time being spent away from the fields of play but have also been postulated to affect student athletes in a number of ways. Etzel, Ferrante and Pinkney ${ }^{3}$ postulated that the occurrence of athletic injuries can sometimes leads to a loss of social status and isolation. But what is also known is that student athletes experience emotional reactions as a result of these athletic injuries. $^{9}$

\section{Psychological Response to Injury}

Athletic injury, as previously mentioned, not only causes physical harm but also presents a challenge to the maintenance of the emotional equilibrium. ${ }^{10}$ Furthermore, the more severe an injury, the more emotional and psychologically traumatic it is to an athlete. ${ }^{10}$ This emotional and psychological impact experienced by injured athletes varies greatly from individual to individual. Some athletes may be injured and experience little to no emotional or psychological reactions, while others may experience quite a bit of emotional anguish as a result of such injuries. Wiese and Weiss ${ }^{11}$ stated that the personal and situational attributes play a major role in determining an individual's emotional and psychological response to an athletic injury. Personal attributes include factors such as level of self esteem, trait anxiety and intrinsic motivation. Situational factors refer to the 
nature of the injury, when the injury occurred and the context in which the injury occurred.

Faris $^{12}$ stated that among the emotional reactions that athletes experience as a result of athletic injury are fear, anger, depression anxiety and panic. Additionally, Beck ${ }^{13}$ added that sustaining an athletic injury also leads to a decrease in an individual's self esteem which can foster the development of irrational thinking. This irrational thinking can lead to athletes either exaggerating the effects of their injury or oversimplifying both the meaning and effect of the injury sustained. Furthermore, athletes may also experience feelings of loneliness, separation, loss of identity and independence because they may perceive that they have let their teammate down and also because they are not contributing to their team. ${ }^{14}$.

Leddy, Lambert and Ogles ${ }^{9}$ in a study conducted among 343 male collegiate athletes investigated the existence of these postulated psychological and emotional reactions. The athletes in this study were assessed on their feeling of depression, selfesteem and anxiety before and after an injury occurred. Results upheld the hypothesis, for injured athletes did reveal that they suffered emotional distress when compared to the control group. The study further indicated that in some instances these reactions reported warranted clinical intervention and further highlighted the significance of using techniques to promote psychological rehabilitation when an athlete is suffering from emotional distress.

Pearson and Jones ${ }^{15}$ also conducted a study to ascertain the emotional responses of injured athletes. This study using a sample of 128 athletes utilized both a qualitative and quantitative approach. Results from the quantitative aspect revealed that injured 
athletes reported more negative moods as opposed to their uninjured counterparts, with emotions such as depression and frustration being most often cited. The qualitative aspect confirmed what had already been reported. Athletes did indeed suffer emotional consequences as a result of injury. This study must be commended for its use of both quantitative and qualitative methods. The former ensured that results were compared to a control group and latter further verified these results via interviews.

\section{Models for Psychological Response to Injury}

Although, it has been generally agreed that athletes do experience emotional and psychological repercussions as a result of athletic injury there has been quite a bit of debate as to how athletes deal with it. One of the ways which have been postulated that athletes deal with injury is that they pass through a sequence of stages on the way to positive adjustment. ${ }^{16}$ Kubler-Ross ${ }^{17}$ was the first to suggest the concept of stages. Kubler-Ross ${ }^{17}$ in her work with over 200 terminally ill patients found upon their diagnosis they, for the most part, reacted in a similar manner. Their reactions were first characterized by denial- a buffer after unexpected news which gave the patient time to mobilize their defenses. This was followed by anger. Upon resolving their anger the patient would start bargaining- attempting to enter some sort of agreement to postpone the inevitable. Depression then follows. Lastly, the patients displayed acceptance having found some peace to their whole situation. ${ }^{17}$

Mc Donald and Hardy ${ }^{18}$ provided support for Kubler-Ross stage theory. They studied the affective response among 5 severely injured Division I athletes ( 2 males and 3 females) for four weeks beginning twenty-four hours after the athletes had sustained their injury. This study confirmed that athletes do experience emotional reactions as a result of 
injury. Furthermore, this study also found that that these reactions, although negative at first, diminished and became positive as rehabilitation progressed. The results from this study largely suggested the stages which athletes go through are very similar to those described by Kubler-Ross. McDonald and Hardy ${ }^{18}$, however, described only two major stages. The first stage includes Shock, Encounter and Retreat. While the second stage simply includes Acknowledgement. Although in agreement with Kubler-Ross, for the most part, they diminished the role of denial in their stage model. ${ }^{19}$

Heil ${ }^{10}$ although in agreement with the stage model proposed an upgraded version. He opposed the view that athletes progress through the aforementioned stage model in a one-time linear process. He instead suggested that an athletes' passage through these stages is more like a cycle that may repeat itself. He proposed that athletes could cycle through three stages- distress, denial and determined coping. ${ }^{10}$ Heil ${ }^{10}$ also stated that at any given time during treatment athletes could regress into the previous stage and their movement through these stages would be very dependent on their self evaluation of the progress being made.

These stage models, however, fail to account for any individual differences. ${ }^{16}$ How one athlete deals with an injury is not necessarily how another athlete deals with it. As a result, it is not safe to state that athletes progress from one stage to another as time elapses after they are injured. Heil ${ }^{10}$ rightly stated that it is not a linear process while also stating that movement through these stages is dependant on the athlete.

Another model which has been postulated as a possible alternative to explain how athletes deal with injuries is the cognitive appraisal model. According to Lazarus ${ }^{20}$ disturbances produced by noxious stimuli sets in motion built in adaptational responses. 
The body then reacts to this stimulus in what is known as secondary appraisal. This involves choosing a coping action which athletes believe will help them overcome this danger. Weiss and Troxel ${ }^{21}$ further added to this theory in a study using ten elite and collegiate athletes. Using primarily an interview format they were able to develop a psychophysiological model. According to this model when the body is injured, demands are placed on it to adapt. The person then evaluates and interprets the situation as threatening or non-threatening causing an emotional response. This emotional response may then trigger psychological responses such as anxiety and frustration.

Brewer $^{16}$ further stated that an individual's appraisal of his/her injury plays a major role in determining his/her emotional response. This cognitive appraisal is influenced by both personal and situational factors. Personal factors such as self esteem, trait anxiety and locus of control influences the appraisal process. Conversely, situational factors such as an individuals' social and physical environment also influences their appraisal. ${ }^{22}$ Consequently, the resulting emotional response is usually dependant on how an injury is perceived in terms of both the aforementioned personal and situational factors.

Although, the previously aforementioned models have been documented in the literature, Brewer ${ }^{16}$ refuted evidence which demonstrated the existence of the stage model, while stating that the cognitive appraisal model provided an ideal guide for future study on athletes' psychological adjustments to injury. Gayman and Crossman ${ }^{23}$ were among those who took up this challenge. Primarily using a qualitative approach among 20 recreational athletes they wanted to determine if the timing of an injury and the season in which it occurred affected an athletes' reaction to the injury. The results revealed that 
as stipulated by the cognitive appraisal model, athletes' reactions to their injuries are dependent on how they were appraised. For instance, the study revealed that an athlete injured in the preseason reacted with much less negative reactions as opposed to an athlete injured during mid season. Conversely, if an athlete sustained an injury at the end of the season and his/her team has a chance of continued play in the post season his/her reactions will be much different, that is more negative. Gayman and Crossman ${ }^{23}$ study highlighted that in dealing with an injured athlete both personal and situational factors should be taken into consideration when evaluating their psychological reactions to an injury. Furthermore, the individual's appraisal of the timing of the injury also influences their psychological reaction to the injury. This study, though, should have employed a much larger sample. This would have ensured that the results would have been more applicable to a greater population.

Injury to athletes, from an objective point of view, may appear to only cause physical damage to an individual. What is often overlooked is the psychological and emotional damage which are sometimes not as discernable. This can potentially have serious ramifications if these responses are not properly dealt with. Consequently, health care practitioners should be much more cognizant of the unseen psychological and emotional responses athletes experience. These psychological and emotional responses can directly influence an individual's readiness to progress with treatment and their eventual movement into the rehabilitation phases of the injury process.

\section{Psychological readiness to participate in rehabilitation}

Rehabilitation is considered crucial to an injured athlete returning to competition. ${ }^{24}$ Athletes are usually ushered into their rehabilitation programs, as 
previously mentioned, when their bodies are, from a medical standpoint, well on the way to returning to their previously uninjured level. Additionally, many health care professionals continue to be very mechanical and technical in their approach to athletic care and treatment viewing athletes' emotional responses as irrelevant. ${ }^{25}$ As a result, much of the focus in treatment tends to be on the physical entity ignoring the emotional and psychological impact.

The overlooking of these emotional and psychological factors could possibly influence athletes' willingness to participate in rehabilitation. Lynch $^{26}$ stated that the emotional impact experienced by an injured athlete can have a significant impact on the rehabilitation process. These emotional and psychological reactions can hinder how athletes approach their rehabilitation ${ }^{18}$ For example, an athlete who is angry at having sustained an injury may not seriously partake in his/ her rehabilitation program, thus delaying the progress he or she will through this program. This delayed progress will inevitable delaying this athlete's return to the field of play. Furthermore, the degree to which athletes deal with these emotional and psychological reactions also influences their passage from treatment to rehabilitation. ${ }^{18}$

However, because rehabilitation has traditionally followed the physical treatment phase in the injury process research with respect to athletes' psychological readiness to participate in rehabilitation has been limited. Additionally, it is generally assumed by medical personnel that injured athletes immediately want to return to the field of play. Very little consideration is given to the fact that athletes must regain emotional control before they are progressed into rehabilitation programs. Yet, despite the relative 
importance of the previously aforementioned concept research has yet to address the psychological readiness of athletes to participate in rehabilitation.

It has, however, been postulated that an assessment of athletes' psychological readiness could give an indication to the medical personnel which athletes are mentally ready to proceed to the rehabilitation phase of the injury recovery process. Consequently, as they become aware of athletes who are not ready for this stage of the injury recovery process suitable interventions could be utilized and appropriate referrals made.

Furthermore, this assessment could possibly help in the construction and tailoring of rehabilitation programs to meet athletes' needs in order to facilitate their entry back to the field of play.

Athletes' participation in rehabilitation programs should be likened to behavioral changes. In most instances their daily routines will be disrupted by having to attend rehabilitation programs in addition to ensuring that their normal activities of daily living don't aggravate their sustained injury. Consequently, completing an assessment to determine their psychological readiness prior to commencing such programs should be considered.

Theories and Models for Behavior Change

Psychological theories have always been used to explain behavioral changes. However, the majority of these theories have been applied in the realm of exercise and exercise adherence and not to rehabilitation. Nonetheless, because participation in rehabilitation programs has already been likened to behavioral changes and because rehabilitation typically involves physical exercise, it is appropriate to consider the theories and models which have been applied to such changes. 


\section{The Health Belief Model}

The Health Belief Model $\left(\mathrm{HBM}^{28}\right)$ is the first of these theories which will be looked at. The HBM states that the likelihood of an individual adopting a behavior is highly dependent on the person's perception of the seriousness of the threat with which they are being faced with and their belief the behavior will have on the threat (see Figure 1). This model, when applied to exercise, assumes that when individuals are about to embark on exercise programs, they evaluate their own health situation and their beliefs exercise will have on it. If the individual believes exercise can improve their health situation they are more likely to embark on such a program. Conversely, if exercise is deemed as not being beneficial such an individual ceases to commence exercising.

The HBM has gained quite strong support for health behaviors and medical compliance but its application to other forms of behavioral changes has been limited. ${ }^{29}$ Heinzelmann and Bagley ${ }^{30}$ were among those who supported the use of the HBM for health behavior. They showed that men who were more prone to coronary heart disease were more likely to participate in exercise programs because they perceived it would reduce their chances of heart disease. However, when applied strictly to behavioral changes such as the adoption of exercise programs by Slenker, Proce, Roberts and Jurs ${ }^{31}$ in a study using joggers and non exercisers, the perceived seriousness of the health threat was found to be relatively weak factor in determining whether an individual chose to exercise. As a result, due to the ambiguity in the data revealed from studies with respect to the HBM, it has been assumed that there is no clear indication that the HBM is appropriate for behavioral change associated with the adoption of exercise behavior. ${ }^{32}$ 
The theory of Reasoned Action $\left(\mathrm{TRA}^{33}\right)$ is another theory that has been postulated for behavioral changes. This theory postulates that a person's intention to perform a behavior is the sole determinant of this action (see Figure 2). This intention results from two basic determinants, one personal and the other social in nature. A personal factor refers to one's attitude towards the behavior, whereas the social factors refer to an individual's attitude towards the behavior he / she is being faced with. Thus, an ensuing decision-making process determines whether a behavior should be adopted. ${ }^{32}$ The TRA has been found to be most applicable to behaviors under an individual's volitional control. Its predictive utility is dramatically reduced when applied to behaviors over which the individual has little to no control. ${ }^{34}$

Sheppard, Hartwick and Warshaw ${ }^{35}$ in a review of studies using a sample of 11,566 , found that prediction of intention was rated higher with a correlation coefficient of (.66) when compared to prediction of behavior's correlation coefficient of (.53). This study thus, provided ample support for the importance of intentions with respect to behavioral change. The TRA was developed to deal with behaviors that are under a person's control and not events that result from these behaviors. However, even though Cooper and Croyle ${ }^{36}$ concluded that the TRA has been responsible for most of the progress in social psychology, Sheppard, Hartwick and Warshaw ${ }^{35}$ work revealed that, despite the TRA's strong predictive utility, more than half of the research that has utilized this model has investigated activities for which this model is not intended i.e. behaviors which were outside an individual's control. 


\section{The Theory of Planned Behavior}

The theory of planned behavior $\left(\mathrm{TPB}^{34}\right)$ was developed as an extension of the TRA. According to this theory, a person's attempt to commence a behavior is highly dependent on, not only one's intentions, the social influence, and the effort exerted, but also on the person's perceived control over factors such as skills, ability, time, and willpower (see Figure 3). Thus, a person will attempt to perform a behavior if he or she believes the advantages outweigh the disadvantages and if they are closely associated with how the person thinks he/ or she should perform the behavior. This person's success will be highly dependant on the control he/ she has over both the internal and external factors, which also influences the attainment of the behavior.

Hausenblas, Carron and Mack ${ }^{37}$, in a meta analysis between TRA and TPB, found that the TPB was a superior model to TRA in accounting for behavior changes such as exercise adoption. Mummery and Wankel ${ }^{38}$ also applied this theory to exercise adoption, using competitive swimmers. They found that swimmers, holding positive attitudes towards their training believing that those important to them thought they trained hard, held positive perceptions about their ability to complete their training. Thus, the TPB predicted significant difference in the measure of training intentions. As a result, they formed stronger intentions to train and were more likely to adhere to their training regimes.

\section{Decision Making Theory}

The Decision Making Theory is yet another theory which must be considered with respect to behavioral change (see Figure 4). This theory postulates that an individual's decision to engage in a behavior is based on his/ her appraisal of the perceived benefits 
versus the perceived costs of the behavior. ${ }^{39}$ This theory when applied to behavioral change can be viewed as a series of decisions. A decisional balance then results when the individual weighs the expected gains versus the expected losses. According to this theory, an individual who is interested in behavioral change must first decide whether he/ she is interested in the new behavior. Secondly, the individual must then decide whether to actually participate in the new behavior. Lastly, once participation in the new behavior has started the individual must then decide whether or not to persist with participation. ${ }^{40}$ It is this last decision which is extremely critical with respect to continuing with a particular behavioral change.

Wankel and Thompson ${ }^{41}$ applied the decision making theory to a 100 females participants who had been inactive for one month. Participants in this study were randomly assigned to one of four treatment groups. Results revealed that participants, who were assigned to the group which used the decision balance sheets, and by extension decision making theory, attended their physical activities more frequently when compared to the control group. Furthermore, this study also highlighted the role decision making theory plays in persuading individuals to embark on behavior change.

\section{Protection Motivation Theory}

The Protection Motivation Theory $\left(\right.$ Rogers $^{42}$ ) must also be considered when looking at behavior change (See figure 5). According to this theory an individual's willingness to participate in a new behavior is heavily dependent on his/her threat appraisal and coping appraisal. Threat appraisal refers to the individual's evaluation of the factors that influence their participation in an unhealthy behavior while coping appraisal refers to the evaluation of the factors that influence engaging in a health behavior. 
This theory has been widely applied to behavior changes as evidence by the results from a meta-analysis conducted by Floyd, Prentice-Dunn, and Rogers ${ }^{43}$ They reviewed 65 studies and overall found that when individuals are faced with increased threat severity and threat vulnerability there was a consequent increase in self efficacy and response efficacy which facilitated the participation in healthy behaviors. Wurtele and Maddux ${ }^{44}$ also examined the utility of the protection motivation model using 160 non exercising graduate students. Participants in this study received a information containing either none, one two, three or four of the separate components of the protection motivation model. Upon reading the message participants were instructed to complete a questionnaire. They were then given a list of options which could be used to achieve aerobic fitness. Results revealed that individuals who perceived themselves to be vulnerable and had high self efficacy were more likely to engage in healthy behavior i.e exercise.

\section{Transtheoretical Model}

The Transtheoretical Model (TTM) of behavior change ${ }^{45}$ is the last model which will be looked at with respect to behavioral change (see Figure 6). The main constructs of this model are the stages of change and the processes of change. This model has proven to be extremely useful in investigating behavioral changes due to this applicability to a wide variety of behaviors. Consequently, this was the model which was chosen for use in this study, and will be discussed in depth in the next section.

\section{The Transtheoretical Model}

The $\mathrm{TTM}^{45}$ has been found to provide an integrative framework for investigating behavioral changes. Additionally, this model has enabled its users to examine / analyze 
the processes which an individual experiences as he/ she embarks on their specified behavioral changes. Commencing a rehabilitation program is usually an aberration from student athletes' daily schedule. As a result it should come as no surprise that it can be likened to adapting a new behavior; a domain for which the TTM has proven to be ideal for investigating. The central organizing constructs of this model are the stages of change and the processes of change. The model has, however, been expanded to include other vitally important constructs such as a series of outcome measures -- decisional balance and self efficacy levels. ${ }^{46}$

\section{Stages of Change}

The Stages of Change, the central construct of the TTM is thought to reflect the varying degrees of readiness experienced by individuals as they embark on new behaviors. ${ }^{47}$ Prochaska $\&$ DiClemente ${ }^{45}$ postulated that the TTM consists of five different stages: precontemplation (no intention of making any changes), contemplation (considering making some changes), preparation (making small changes), action (actively participating in the new behavior) and maintenance (continuing the new behavior over an extended period of time). These aforementioned stages are important because they focus not only on the changes exhibited in behavior but also on the changes exhibited in behavioral intentions. ${ }^{47}$ Prochaska and DiClemente ${ }^{45}$ additionally stated that progress through the stages is not considered linear but is instead thought to occur cyclically. This cyclical passage through the stages accounts for the fact that many individuals usually make many attempts at behavioral change before it is accomplished ${ }^{47}$ Sonstroem ${ }^{48}$ also further intensified the claim by stating that behavioral change is not an all or none process but instead one in which individuals may take some time to accomplish their 
desired behavioral change. Lastly, the dynamic nature of this measure has allowed researchers to move towards a more predictive models thus allowing behavioral change to be better understood. ${ }^{49}$

The Stages of Change has been widely applied to a variety of behavioral changes. Among the behavioral changes to which it has been applied is smoking cessation. Prochaska and DiClemente ${ }^{45}$ in a study used 872 subjects who were either in the process of changing their smoking habits or had already done so. Participants were representative of each of the five stages of the Stages of Change- precontemplation, contemplation, preparation, action and maintenance. Although, this was one of the earliest applications of the stages of change to behavioral modification results revealed that participants in this study regardless of whether they had stopped smoking on their own or via treatment were found to have progressed through four of the five stages of change. Participants revealed that they experienced precontemplation - thinking about stopping smoking, preparationbecoming decided about stopping, action- modifying their habits or environment and maintenance- maintaining the habit of not smoking. .

The Stages of Change has also been extensively applied to exercise adherence. Hellman ${ }^{50}$ used a sample of 349 older adults, aged 65 and older, with cardiac diagnosis who had recently been discharged from inpatient therapy. Participants were interviewed over the telephone about their exercise behaviors using the stage of exercise adherence measure, modified 7-day activity interview, exercise benefits/barriers scale, self efficacy for exercise, and processes of change in exercise adherence. Results revealed that perceived self efficacy, perceived benefits of exercise and perceived barriers to exercise were significant predictors of exercise adherence. Furthermore, the stages of change 
model was supported. The amount of time participants engaged in exercise was found to have increased significantly with each subsequent stage from precontemplation to maintenance.

More recently the Stages of Change has been adapted for use within the field of sport psychology. Grove, Norton, Van Raalte, and Brewer ${ }^{51}$ using a sample of 37 youth basketball players used the stages of change to determine if individuals exposed to a mental skills training program will progress to the action oriented stages as a result of their exposure to mental skills. The participants were divided into a treatment group (received exposure to mental training) and a control group (who received no exposure to mental training). The stages of change questionnaire were administered at the beginning of the study, at its conclusion and three months after the study had been concluded. Results revealed that participants did in fact progress to the action oriented stages as $40 \%, 90 \%$, and $75 \%$ for the pretest, post test and three months post respectively deemed themselves to be in the action/maintenance stage. These results, not only, indicated the utility of the stages of change instrument with respect to sport psychology but also the progression participants made towards permanently adopting the use of mental skills, which can be considered very similar to the adopting of new behaviors.

These aforementioned studies showed the adaptability of the stages of change construct of TTM to a variety of behavioral changes. These two studies used large samples sizes so the results could be applied to the general population but the self reporting nature of this measure raises concern of the possibility of the self reporting bias. However, this should not downgrade the fact that the stages of change has been found to work across a variety of behavioral changes. 
However, it must be mentioned, that although the stages of change has been extensively applied to behavioral changes with respect to exercise adoption it application to the rehabilitation setting has been quite limited until Wong. ${ }^{52}$ Wong $^{52}$ has been the lone investigator thus far to apply the concept of stages of change to the rehabilitation setting. Wong ${ }^{52}$ using a sample of 96 injured athletes attempted to determine the processes of change identified by injured athletes while also trying to establish if these processes differed according to athletes' stage of rehabilitation. Participants' stages of change with respect to rehabilitation were determined via a self reported modified Stages of Change Instrument. The stages were modified to state precontemplation (not attending rehabilitation, not thinking about beginning to attend), contemplation (not attending rehabilitation, thinking about starting to regularly rehabilitate injury), preparation (currently rehabilitating injury, but not regularly), action (currently rehabilitating injury regularly, but did not regularly rehabilitate when the injury first occurred) and maintenance (currently rehabilitating injury and have done so since injury occurred and plan on continuing until fully recovered) Wong. ${ }^{52}$ Results revealed that athletes self reported themselves to be in contemplation, preparation, action or maintenance. Thus, it is possible that the stages of change which have been found to exist for individuals as they embark on behavioral changes such as exercise adoption and smoking cessation do exist within the rehabilitation settings.

Processes of Change

The other central construct of the TTM is the processes of change. Processes of change are thought to be both concealed and unconcealed activities which individuals engage in as they progress through the stages of change enroute to behavioral change. ${ }^{46}$ 
Ten processes of change $\mathrm{e}^{45}$ have been postulated to exist. The processes of change are as follows:

Consciousness Raising- increasing the information available to individuals so they can make effective responses.

Dramatic Relief- releasing from suppression blocked emotions by extrinsic emotional observations

Environmental Reevaluation-altering an individual's perception of his/ her behavior's effects on the environment

Social Liberation- society changing to provide more alternatives for problem behaviors Self Reevaluation- altering one's perceptions regarding the effects of a particular behavior on oneself

Self Liberation- freeing oneself of old beliefs and behaviors, become aware of new possibilities.

Stimulus Control- altering the way we respond to a stimulus that had been controlling our behavior

Helping Relationships- support from others during behavior change

Counter Conditioning- altering the way we respond to a stimulus that had been controlling our behavior

Reinforcement- altering the contingencies which reinforce and maintain a behavior.

The aforementioned ten processes have been divided into two higher order constructs- experiential processes and behavioral processes. ${ }^{47}$ Experiential processes focus on the internal experiences individuals encounters while attempting to change their behaviors. Conversely, behavioral processes are the more overt activities which 
individuals utilize during their attempt at behavior change. ${ }^{53}$ The first five processes, as listed above, are thought to be experiential in nature and mostly utilized during the earlier stages of behavioral modification. ${ }^{46}$ The latter five processes are considered behavioral and are most often used in the latter stages of behavioral modification. ${ }^{46}$ Consequently, whether or not an individual uses these processes depends heavily on their stage of change. $^{45}$

Marcus, Rossi, Selby, Niaura and Abrams ${ }^{47}$ applied the processes of change to exercise adoption and maintenance in a worksite sample. They used a sample of 1,172 male and female employees from both a retail outlet and an industrial manufacturer. Participants in this study were made to complete questionnaires with respect to their exercise behavior. These questionnaires were then analyzed to determine the extent to which participants' utilized the processes of change during exercise adoption. Results revealed that the participants made use of all the 10 processes of change. Additionally, usage of these processes was very found to be highly correlated to each participant's stage of change. Precontemplators were found to generally have utilized the processes of change much less than those who were deemed to be in other stages. Preparers were found to have utilized behavioral processes more often than contemplators although it was found that the use experiential processes did not differ across the stages. Actors used both experiential processes and behavioral processes more often than preparers.

Furthermore, there was a noted decrease in the use of experiential processes but not in behavioral processes for those participants in maintenance stage when compared to those in the action stage. As a result, it can be inferred from this investigation that as individuals progress through the stages of change from precontemplation to maintenance, 
enroute to behavior modification there is a distinct shift in the utilization of the processes of change. That is, there is a decrease in the use of experiential processes with a corresponding increase in the use behavioral processes. This is because as individual progress through the stages of change they will begin to utilize activities which are more inclined to help them embark on their behavior change (behavioral processes) as opposed to focusing on feelings associated with their impending behavior change.

Wong $^{52}$ expanded the use of the TTM when she explored the relationship between the perceived processes of change medical personnel believe injured athletes undergo versus the self reported processes of change of injured athletes during injury rehabilitation. Wong ${ }^{52}$ used a sample of 96 injured athletes and 12 sports medicine providers. They were provided with questionnaires to ascertain the processes of change which they perceived injured athletes experience (sport medicine providers) and the processes of change they believe they undergo (injured athletes). Results revealed that injured athletes thought they utilized all ten processes of change as they progressed through the stages of change from precontemplation to maintenance. Sports medicine providers also revealed that they believed athletes utilized all ten of the processes of change as they progress through the stages of change. However, Marcus, Rossi, Selby, Niaura and $\mathrm{Abrams}^{47}$ in a previous study stated that precontemplators used much less of the ten processes. Yet, Wong ${ }^{52}$ found that the use of processes of change seemed to be the same across all the stages of change. It was, however, revealed that the general utilization of behavioral processes were found to be statistically higher than those that of the experiential processes across the stages. These results were also quite similar to those obtained from Marcus, Selby, Niaura, and Rossi ${ }^{49}$ who also found that individuals rely 
more heavily on experiential processes in the earlier stages and more on the behavioral processes in the later part of their stages of change.

Udry, Shelbourne and Gray ${ }^{27}$ in a study using 121 pre anterior cruciate ligament surgery participants attempted to determine their preoperative psychological readiness using an adapted version of the Psychological Readiness for Change Model (also referred to as the TTM). Udry, Shelbourne and $\mathrm{Gray}^{27}$ used only the processes of change, decisional balance and self efficacy aspects of the TTM. Participants were asked to complete questionnaires to determine the extent to which they utilized the ten processes of change. Results from this study revealed that in terms of the 10 processes of change, self liberation, helping relationships and social liberation were the most often utilized processes of change. Conversely, it was also found that consciousness raising and stimulus control were found to be the least used processes. The results also revealed a greater tendency on the parts of the participants to use the behavioral processes as opposed to the experiential processes.

\section{Self Efficacy}

The TTM, as previously mentioned, also incorporates a number of other additional measures. Among these other measures is a self efficacy measure. Self efficacy refers to the confidence an individual has in his/ her own ability to complete a task or behavior. ${ }^{46}$ This measure was derived from the Self Efficacy Theory (Bandura ${ }^{54}$ ). This theory postulates that performance of a specific behavior is strongly influenced by an individual's confidence in his/ her ability to perform the behavior (Bandura $\left.{ }^{54}\right)$. Bandura ${ }^{54}$ stated that individuals who exhibit high levels of confidence or efficacy expectations for a given task are more likely to successfully engage in that particular task. 
Self efficacy beliefs have been found to be closely associated with behaviors such as smoking cessation. ${ }^{55}$ Condiotte and Lichtenstein ${ }^{55}$ attempted to validate Bandura's self efficacy theory using 78 smokers from two cessation programs. Participants from these two programs were assigned to either a maximal or minimal recording group. They were assessed using measures to determine their smoking behaviors and self efficacy prior to being administered an intervention. They were then treated with the said intervention followed by a post-treatment assessment of their self efficacy and smoking behaviors. Results revealed that perceived self efficacy increased as a result of the intervention. Furthermore, self efficacy levels were also found to significantly increase as a result of both treatment programs. Further analysis of the results revealed that those subjects who had relapsed had lower self efficacy scores when compared to those who were found to have been successful in quitting. The results of this study was corroborated by DiClemente, Prochaska and Gibertini ${ }^{56}$ who found smoking self efficacy to be related to stages of change with precontemplators exhibiting low levels of self efficacy while those in maintenance reported high levels of self efficacy.

Self efficacy as a measure has been widely applied to injury rehabilitation. Theodorakis et al. ${ }^{57}$ were among those who applied this measure to injury rehabilitation. Using a sample of 91 injured participants they wanted to determine the effect that goal setting had on self efficacy on subjects as they progressed through their injury rehabilitation. Subjects were divided into two experimental groups and one control group. The experimental group completed goal setting, self efficacy and self motivation scales. Conversely the control group did not. Results revealed that subjects in both experimental groups experienced significant performance increases in addition to reporting increased 
self efficacy levels. From the results it seemed like the more confident subjects (those with higher self efficacy) the higher their performance.

Similarly, Wong ${ }^{52}$ used the self efficacy measure from the TTM and applied it to

rehabilitation by Wong. ${ }^{52}$ Her study revealed that a significant relationship exists between self efficacy and stages of change. Additionally, it was also revealed that self efficacy scores were found to be higher among those injured athletes in the maintenance stage when compared to those in action. Furthermore, self efficacy scores in the action stage were found to be higher than those in the preparation stage. As a result, it is within reason to assume that an individual's self efficacy increases as he/ she progresses through their stages of change. This study also confirmed that self efficacy is a good predictor of stages of change.

\section{Decisional Balance}

The last of the constructs which have been incorporated in the TTM is the decisional balance measure. The decisional balance construct is as an analysis by an individual of the pros and cons of commencing a new behavior. This construct was initially derived from the Decision Making Model. ${ }^{39}$ The original Decision Making Model $^{39}$ consisted of four categories of pros and four categories of cons. Each of these four categories were instrumental gains for self and others and instrumental costs for self and others. However, Velicer, DiClemente, Prochaska and Brandenberg ${ }^{58}$ after performing empirical tests found that using only pros and cons for this measure to be much more beneficial. Consequently, the decisional balance measure using only pros and cons as we know it has been in existence since then. Although this decision making 
model has been used in lifestyle changes associated with quitting smoking ${ }^{58}$ and with exercise $^{59}$ this model has not been applied in the rehabilitation setting.

Udry, Shelbourne and Gray ${ }^{27}$ have, however, applied decisional balance to preoperatively to anterior cruciate ligament patients. Their study revealed that participants generally rated more pros than cons with respect to their upcoming surgery and the rehabilitation programs to follow. Consequently, it will be within reason to expect that injured athletes would similarly rate their impending rehabilitation programs similarly; more pros than cons.

Decisional balance has, however, been extensively applied in the exercise realm. Marcus, Rakowski and Rossi ${ }^{59}$ in a study used 778 men and women from four different worksites to determine their motivational readiness for exercise adoption. Participants were then given questionnaires to complete to ascertain their decisional balance and their stage of exercise adoption. Results revealed that the decisional balance measures varied across the stages of exercise adoption. The cons associated with exercise adoption drastically outweighed the pros during precontemplation and contemplation. However, for those in the action and maintenance stages, the pros outnumbered the cons. It was also revealed that participants in preparation stage reported a balance between the pros and the cons.

Other variables affecting Adherence to Rehabilitation Programs

The most salient goal of rehabilitation is to return injured athletes to their prior level of functioning. ${ }^{60}$ Consequently, if all things were equal we could expect that all injured athletes would smoothly and efficiently progress through rehabilitation and quickly return back to the field of play. However, such an ideal situation rarely occurs. 
For whatever reason, there are those athletes who thoroughly engross themselves in rehabilitation, while there are those who have a much more listless approach to theirs. As a result, it should come as no surprise that many medical personnel often wonder why some athletes adhere to their rehabilitation programs and others do not. ${ }^{61}$ What is known though, is that athletes face a number of factors which influence not only their approach to rehabilitation but more importantly their adherence to these programs.

Adherence to rehabilitation programs can be usually assessed by athletes' attendance and fully committed participation in the process. ${ }^{62}$ However, athletes have been found to drop out or fail to properly adhere and comply to even the best conceived rehabilitation programs. ${ }^{24}$ As a result, adherence to rehabilitation programs has now become quite problematic. ${ }^{63}$ However, despite the rising significance of this problem research within the area still appears to be lacking. ${ }^{64}$ Consequently, in order for medical personnel to get a better idea on how to deal with this potentially serious problem idea must be derived from studies done on adherence to therapeutic exercises, cardiac rehabilitation and medical treatments. ${ }^{64}$

Meichenbaum and Turk $^{66}$ were among the few to initially conduct research in the area of adherence and compliance to rehabilitation programs and they reported that there are many variables which influence adherence and compliance. These variables were postulated to vary widely from physiological to medical and even to psychological reasons. Brewer ${ }^{63}$ in a recent review on adherence to rehabilitation programs narrowed down these variables by stating two of the most common factors which determine whether an athlete adheres to his or her rehabilitation program. According to Brewer ${ }^{63}$ these two factors are personal and situational. Personal factors have been postulated to 
include self motivation, self confidence, task involvement, tough mindedness and trait anxiety. Situational factors include comfort of the athletic training environment, convenience of the rehabilitation scheduling, and social support within the rehabilitating environment.

Fisher, Domm and Wuest ${ }^{24}$ were among the first to conduct research on adherence to rehabilitation programs with respect to injured collegiate athletes. This study employed the use of 41 injured collegiate athletes who were asked to complete a rehabilitation adherence questionnaire focusing on areas such as perceived exertion, pain tolerance, self motivation, social support, scheduling and environmental factors. Analysis of these completed questionnaires revealed that athletes who were found to have adhered more to their rehabilitation programs revealed a combination of personal and situational factors which influenced their adherence to rehabilitation programs. Personal factors found to significantly influence rehabilitation adherence included self motivation, pain tolerance and support systems whereas the situational factors included rehabilitation schedules and environment.

Duda, Smart and Tappe ${ }^{65}$ in a later study done employing the use of a similar size sample to the previously aforementioned study (41 male and female intercollegiate athletes) examined the relationship between adherence to rehabilitation programs and factors such as personal incentives, sense of self and perceived behavioral predictions. Results from this study proved to be quite similar to those obtained in the study done by Fisher, Domm and Wuest. ${ }^{24}$ These were adherence to rehabilitation programs are based on personal factors such as motivation, task involvement and perception of the efficacy of treatment. A multiple regression analysis did, however, reveal that belief in the efficacy 
of treatment, of all the aforementioned factors, accounted for the greatest amount of variance in adherence to rehabilitation programs. Even though, both of these were among the earliest studies done they both revealed some very critical data with respect to adherence to rehabilitation program for injured collegiate athletes. Although, both studies revealed similar findings, they would be much more applicable to the injured population if larger samples had been utilized.

\section{Models for Adherence to Rehabilitation Programs}

Although such studies have revealed that both personal and situational factors influence adherence to rehabilitation programs, these factors do not work independent of each other. They, however, do both fit into the theoretical models which have been postulated with respect to adherence to rehabilitation programs. The first of these models is the Personal Investment Theory by Maehr and Braskamp. ${ }^{67}$ According to this model motivation to adhere and comply to a rehabilitation program is influenced by personal incentives, sense of self belief, perceived options, and factors influencing the interaction between the person and the environment (Maehr and Braskamp ${ }^{67}$ ). This theory was the subject of a study by Duda, Smart and Tappe. ${ }^{65}$ Duta, Smart and Tappe ${ }^{65}$ wanted to determine if any relationship existed between the basic tenets of the Personal Investment Theory: personal incentives, sense of self belief, perceived options, and factors influencing the interaction between the person and the environment. This study revealed that these factors were indeed significant predicators of adherence. It must, however, be mentioned that personal factors of all the basic tenets of the Personal Investment Theory were found to have much less of an effect on adherence when compared to the other factors such as sense of self and perceived options. . 
The Protection Motivation Theory is another theory which has been applied to adherence to rehabilitation programs. Rogers ${ }^{42}$ stated that adherence to rehabilitation programs is highly influenced by the perceived severity of injury, susceptibility to further complications, belief of efficacy of treatment and rehabilitation self efficacy. Taylor and May $^{68}$ were among the first to conduct studies applying the Protection Motivation Theory. They conducted their study using 62 competitive athletes and found that the basic tenets of this model were positively associated with adherence to rehabilitation programs. A subsequent study done by Brewer et al. ${ }^{69}$ addressed some of the limitations of the previous study. Brewer et al. ${ }^{69}$ employed the use of a sample which was homogeneous with respect to sport, injury type, and rehabilitation protocols. In addition, this study also addressed adherence with respect to both home and clinic based rehabilitation programs. Its results were very similar to those obtained in the preceding study, but were much more valid as a result of the changes which had addressed some of the previous study's limitations.

\section{Summary}

Despite the numerous studies which have shown that athletes do sometimes experience emotional and psychological reactions as a result of athletic injury health care professionals still persist in being very mechanic and technical in their approach to athletic care often disregarding athletes' emotional responses. ${ }^{25}$ Consequently, athletes are ushered into their rehabilitation programs when their bodies are, from a medical standpoint, well on the way to returning to their previously uninjured level. This progression is usually done with little regards for these athletes' psychological readiness for rehabilitation. 
It must, however, be noted that even though athletes commence rehabilitation when they have been deemed physically healed their adherence to these rehabilitation programs have also presented itself as a problem. Some athletes have been found to thoroughly engross themselves in rehabilitation, while there are those who have a much more listless approach to theirs. Furthermore, athletes have been found to drop or fail to properly adhere to even the best conceived rehabilitation programs (Fisher, Domm, \& Wuest, 1988). However, despite its significance and the increasing nature of the problem research with respect to injury rehabilitation adherence is still very limited (Fisher, 1990).

Furthermore, athletes' psychological readiness for rehabilitation takes on added significance when one considers that commencing these rehabilitation programs can be, liken to a behavioral change. Injured athletes instead of attending practice now have to spend increased time in the training room and have to be even more careful and alert during activities of daily living to avoid aggravating their injuries.

Consequently, it is the purpose of this study to assess the psychological readiness of athletes and its influence on rehabilitation adherence, compliance and perceived versus actual completion rates using the TTM. The TTM has proven to be the most suited model to assess behavioral changes and includes constructs to assess an individual's stage of change, processes of change, decisional balance and self efficacy. Although, it has not been itself in the injury rehabilitation, the only way this can be done is with its continued application in this area. Udry, Shelbourne and Gray (2003) were able to measure the psychological readiness of pre surgery patients using this model. These patients were found to exhibit advancement within the stages of change, high levels of self efficacy and utilized more behavioral as opposed to experiential processes of change. It is hoped that 
the proposed study will be able to show that psychological readiness assessed by the TTM influences adherence and compliance to rehabilitation programs. Additionally, the impact of psychological readiness will also be looked at with respect to perceived versus actual time spent in rehabilitation. 


\section{REFERENCES}

1. National Collegiate Athletic Association. (2004). [Online]. Available: http://www.ncaa.org [2004, March 15].

2. Watt SK, Moore JL. Who are student athletes? New Directions for Student Services. 2001; 93: 7-18.

3. Etzel EF, Ferrante AP Pinkney JW. Counseling college studentathletes: Issues and Interventions. Morgantown, WV: Fitness Information Technology; 1996

4. Street JM. Self-efficacy: A tool for providing effective support services for student-athletes. In S. Robinson (Ed.), Gaining the Competitive Edge: Enriching the Collegiate Experience of the New Student-Athlete. Columbia: National Resource Center for the First Year Experience and Students in Transition, University of South Carolina; 1999

5. Etzel EF. Life stress, locus of control, and competition anxiety patterns of college student-athletes. Unpublished doctoral dissertation, West Virginia University; 1989.

6. Andersen MB, Williams JM. (1988). A model of stress and athletic injury: Prediction and prevention. Journal of Sport \& Exercise Psychology. 1998; 10: 294-306.

7. Bramwell ST, Masuda M, Wagner NN, Holmes TH. Psychosocial factors in athletic injuries: Development and application of the social and athletic readjustment rating scale. Journal of Human Stress. 1975; 1: 6-20.

8. Kerr G, Minden H. Psychological factors related to the occurrence of athletic injuries. Journal of Sport \& Exercise Psychology. 1988; 10: 167-173.

9. Leddy MH, Lambert MJ, Ogles BM. Psychological consequences of athletic injury among high-level competitors. Research Quarterly for Exercise and Sport. 1994; 65: 347-354.

10. Heil J. Psychology of sport injury. Roanoke, VA: Human Kinetics Publishers; 1993.

11. Weise DM, Weiss MR. Psychological rehabilitation and physical injury: Implications for the sportsmedicine team. The Sport Psychologis. 1987; 1: 318330 .

12. Faris G J. Psychologic aspects of athletic rehabilitation. Clinics in Sports Medicine. 1985; 4: 545-551. 
13. Beck A. Cognitive Therapy: Nature and relation to behavior therapy. Behavior Therapy. 1970; 2: 27-78.

14. Lewis-Griffith L. (1982). Athletic injuries can be a pain in the head too. Women's sport. 1982; 4: 44-54.

15. Pearson L, Jones G. Emotional effects of sports injuries: Implications for physiotherapists. Physiotherapy. 1992; 78: 762-770.

16. Brewer B. Review and critique of methods of psychological adjustment to athletic injury. Journal of Applied Sport Psychology. 1994; 6: 87-100.

17. Kubler-Ross E. On death and dying. New York, NY: Macmillan Publishing; 1969.

18. McDonald SA, Hardy CJ. (1990). Affective response patterns of the injured athlete: An exploratory analysis. The Sports Psychologist. 1990; 4: 261-274.

19. Booher JM, Thibodeau GA. Athletic injury assessment. Boston, MA: McGraw Hill; 2000.

20. Weiss MR, Troxel RK. Psychology of the injured athlete. Athletic Training. 1986; 21: 104-109.

21. Lazarus RS. Psychological stress and the coping process. New York, NY: McGraw Hill; 1966.

22. Crossman J. A qualitative analysis of how timing of the onset of sports injuries influences athlete reactions. Journal of Sport Behavior. 2000; 26: 255- 269.

23. Gayman AM, Crossman J. A qualitative analysis of how the timing of the onset of sports injuries influences athlete reactions. Journal of Sport Behavior. 2003; 26: $255-272$.

24. Fisher AC, Domm MA, Wuest DA. Adherence to sports injury rehabilitation programs. The Physician and Sportsmedicine. 1988; 16: 47-52.

25. May JR, Sieb GE. Athletic injuries: Psychosocial factors in the onset sequelae, rehabilitation and prevention. In J.R. May \& M.J. Ashen (Eds.), Sports Psychology (pp. 340-350). San Diego, CA: PMA Publishing; 1987.

26. Lynch GP. (1988). Athletic injury and the practicing sport psychologist: Practical guide-lines for assisting athletes. The Sport Psychologist. 1988; 2: 161-167. 
27. Udry E, Shelbourne KD, Gray T. Psychological readiness for anterior cruciate ligament surgery: Describing and comparing the adolescent and adult experiences. Journal of Athletic Training. 2003; 38: 167-171.

28. Becker MH, Maiman LA. Sociobehavioral determinants of compliance with health care and medical care recommendations. Medical Care. 1975; 13: 10-24.

29. Gill DL. Psychological dynamics of sport and exercise. Champaign, IL: Human Kinetics; 2000.

30. Heinzelmann P, Bagley RW. Response to physical activity programs and their effects on health behavior. Public Health Reports. 1970; 85: 905-911.

31. Slenker SE, Price JH, Roberts SM, Jurs SG. Joggers versus non exercisers: An analysis of knowledge, attitudes and beliefs about jogging. Research Quarterly for Exercise. 1985; 55: 371-378.

32. Dishman R. Advances in exercise adherence. Champaign, IL: Human Kinetics; 1994.

33. Fishbein M, Ajzen I. Belief, attitude, intention and behavior. Don Mills, NY: Addison-Wesley; 1975.

34. Ajzen I. From intention to actions: A theory of planned behavior. In J. Kuhl \& J. Beckman (Eds.), Action-control: From cognition to behavior (pp. 11-39). Berlin Germany: Springer; 1985.

35. Sheppard BH, Hartwick J, Warshaw PR. The theory of reasoned action: A meta analysis of point research with recommendations for modifications and future research. Journal of Consumer Research. 1998; 15: 325-343.

36. Cooper J, Croyle RT. Attitude and attitude change. Annual Review of Psychology. 1984; 35: 395-426.

37. Hausenblas HA, Carron AV, Mack D. Application of the theories of reasoned action and planned behavior to exercise behavior: A meta analysis. Journal of Sport \& Exercise Psychology. 1997; 19: 36-51.

38. Mummery KW, Wankel LM. Training adherence in adolescent competitive swimmers: An application of the theory of planned behavior. Journal of Sport \& Exercise Psychology. 1999; 21: 313-328.

39. Janis JL, Mann L. Decision making: A Psychological analysis of conflict, choice and commitment. New York: Free Press; 1977. 
40. Kendzierski, D. Schema theory: An information processing focus. In R. Dishman (Ed.), Advances in exercise adherence (pp. 131-161). Champaign, IL: Human Kinetics; 1994.

41. Wankel LM, Thompson C. Motivating people to be physically active: Selfpersuasion vs balanced decision making. Journal of Applied Social Psychology. 1977; 7: 332-340.

42. Rogers RW. A protection motivation theory of fear appraisals and attitude change. Journal of Psychology. 1975; 91: 93-115.

43. Floyd DL, Prentice-Dunn S, Rogers, RW. A meta-analysis of research on protection motivation theory. Journal of Applied Sport Psychology. 2000; 30: 407-429.

44. Wurtele SK, Maddux JE. Relative contributions of protection motivation theory components in predicting exercise intentions and behaviors. Health Psychology. 1987; 6: 453-466.

45. Prochaska JO, DiClemente CC. (1983). Stages and processes of self-change in smoking: Toward an integrative model of change. Journal of Consulting \& Clinical Psychology. 1983; 51: 390-395.

46. Velicer WF, Prochaska JO, Fava JL, Norman GJ, Redding CA. (1998). Smoking cessation and stress management: Applications of the transtheoretical model of behavior change. Homeostasis. 1998; 38: 216-233.

47. Marcus BH, Rossi JS, Selby VC, Niaura RS, Abrams DB. (1992). Process of change questionnaire. Health Psychology. 1992; 11: 386-395.

48. Sonstroem RJ. Psychological models. In R. Dishman (Ed.), Exercise adherence (pp. 125-154). Champaign, IL: Human Kinetics; 1988.

49. Marcus BH, Selby VC, Niaura RS, Rossi JS. (1992). Self efficacy and the stages of exercise behavior change. Research Quarterly for Exercise and Sport. 1992; 63: 60-66.

50. Hellman EA. Use of the stages of change in exercise adherence model among older adults with a cardiac diagnosis, Journal of Cardiac Rehabilitation. 1997; 17: $145-155$.

51. Grove JR, Norton PJ, Van Raalte JL, Brewer B. Stages of change as an outcome measure in the evaluation of mental skills training program. The Sports Psychologist; 13: 107-116. 
52. Wong IE. Injury Rehabilitation Behavior: An Investigation of Stages and Processes of Change in the Athlete-Therapist Relationship. Unpublished master's thesis, University of Oregon; 1998.

53. Prochaska JO, Velicer WF. The Transtheoretical Model of health behavior change. American Journal of Health Promotion. 1997; 12: 38-48.

54. Bandura A. Self efficacy: Towards a unifying theory of behavior change. Psychological Reviews. 1977; 84: 191-215.

55. Condiotte MM, Lichtenstein E. Self-efficacy and relapse in smoking cessation programs. Journal of Consulting and Clinical Psychology. 1981; 49: 648-658.

56. DiClemente CC, Prochaska JO, Gibertini M. Self-efficacy and the stages of self change of smoking. Cognitive Therapy and Research. 1985; 9: 181-200.

57. Theodorakis Y, Maliou P, Papaioannou A, Beneca A, Filactakidou A. The effect of personal goals, self efficacy, and self satisfaction on injury rehabilitation. Journal of Sport Rehabilitation. 1996; 5: 214-223.

58. Velicer WF, DiClemente CC, Prochaska J, Brandenburg N. A decisional balance measure for assessing and predicting smoking status. Journal of Personality and Social Psychology. 1985; 48: 1279-1289.

59. Marcus BH, Rakowski W, Rossi JS. Assessing motivational readiness and decision making for exercise. Health Psychology. 1992; 11: 257-261.

60. Ninedek A, Kolt GS. Sport physiotherapists' perceptions of psychological strategies in sport injury rehabilitation. Journal of Applied Sport Psychology. 2000; 10: 75-83.

61. Fisher AC, Mullins SA, Frye PA. Athletic trainers' attitudes and judgments of injured athletes' rehabilitation adherence. Journal of Athletic Training. 1993; 28: 43-47.

62. Byerly PN, Womel T, Gahemer J, Domholdt E. Rehabilitation compliance in an athletic training environment. Journal of Athletic Training. 1994; 29: 352-361.

63. Brewer BW. Adherence to sport injury rehabilitation programs. Journal of Applied Sport psychology. 1998; 10: 70-82.

64. Fisher AC. Adherence to sports injury rehabilitation programs. Sports Medicine. 1990; 9: 151-158. 
65. Duda JL, Smart AE, Tappe MK. Predictors of adherence in rehabilitating athletic injury: An application of personal investment theory. Journal of Sport \& Exercise Psychology. 1989; 11: 367-381.

66. Meichenbaum D, Turk DC. Facilitating treatment adherence. New York, NY: Plenum Publishing; 1987.

67. Maehr ML, Braskamp LA. The motivation factor: A theory of personal investment. Lexington, Mass: Lexington Books; 1986.

68. Taylor AH, May S. Threat and coping as determinants of compliance to sport injury rehabilitation: An application of protection motivation theory. Journal of Sports Sciences. 1996; 14: 471-482.

69. Brewer BW, Cornelius AE, Van Raalte JL, Peptipas AJ, Sklar JH, Pohlman M. H, Krushell RJ, Detmar TD. (2003). Protection motivation and adherence to sports injury rehabilitation revisited. The Sports Psychologis. 2003; 17: 95-103. 